Supplement of

\title{
Cloud water composition during HCCT-2010: Scavenging efficiencies, solute concentrations, and droplet size dependence of inorganic ions and dissolved organic carbon
}

Dominik van Pinxteren et al.

Correspondence to: Hartmut Herrmann (herrmann@ tropos.de)

The copyright of individual parts of the supplement might differ from the CC-BY 3.0 licence. 


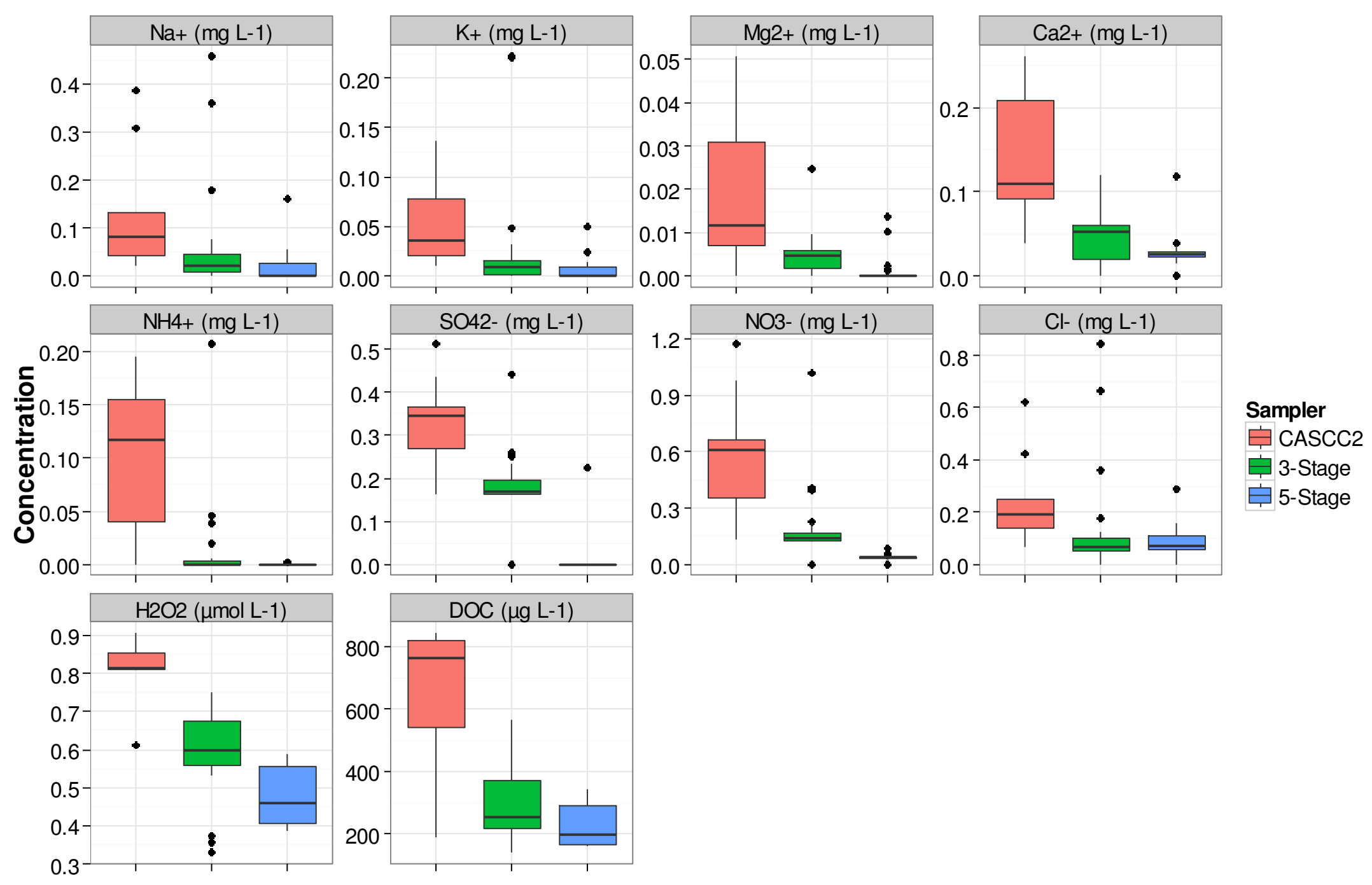

Figure S1: Box-plots of concentration levels of inorganic ions, H2O2, and DOC in control samples ("blanks") from 3 cloud water collectors. 


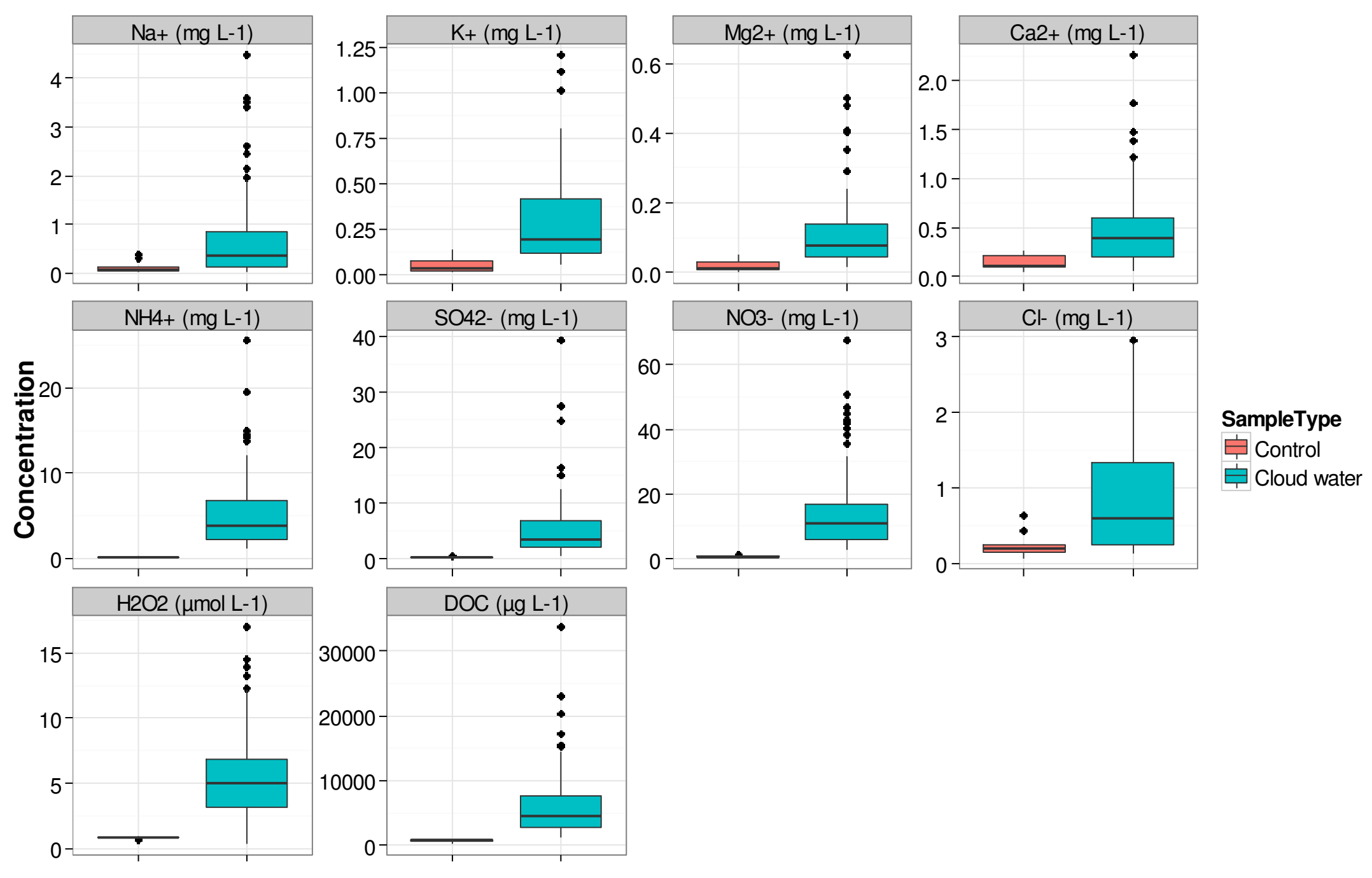

Figure S2: Box-plots of concentration levels of inorganic ions, H2O2, and DOC in control samples of bulk collector (CASCC2) and bulk cloud water samples. 


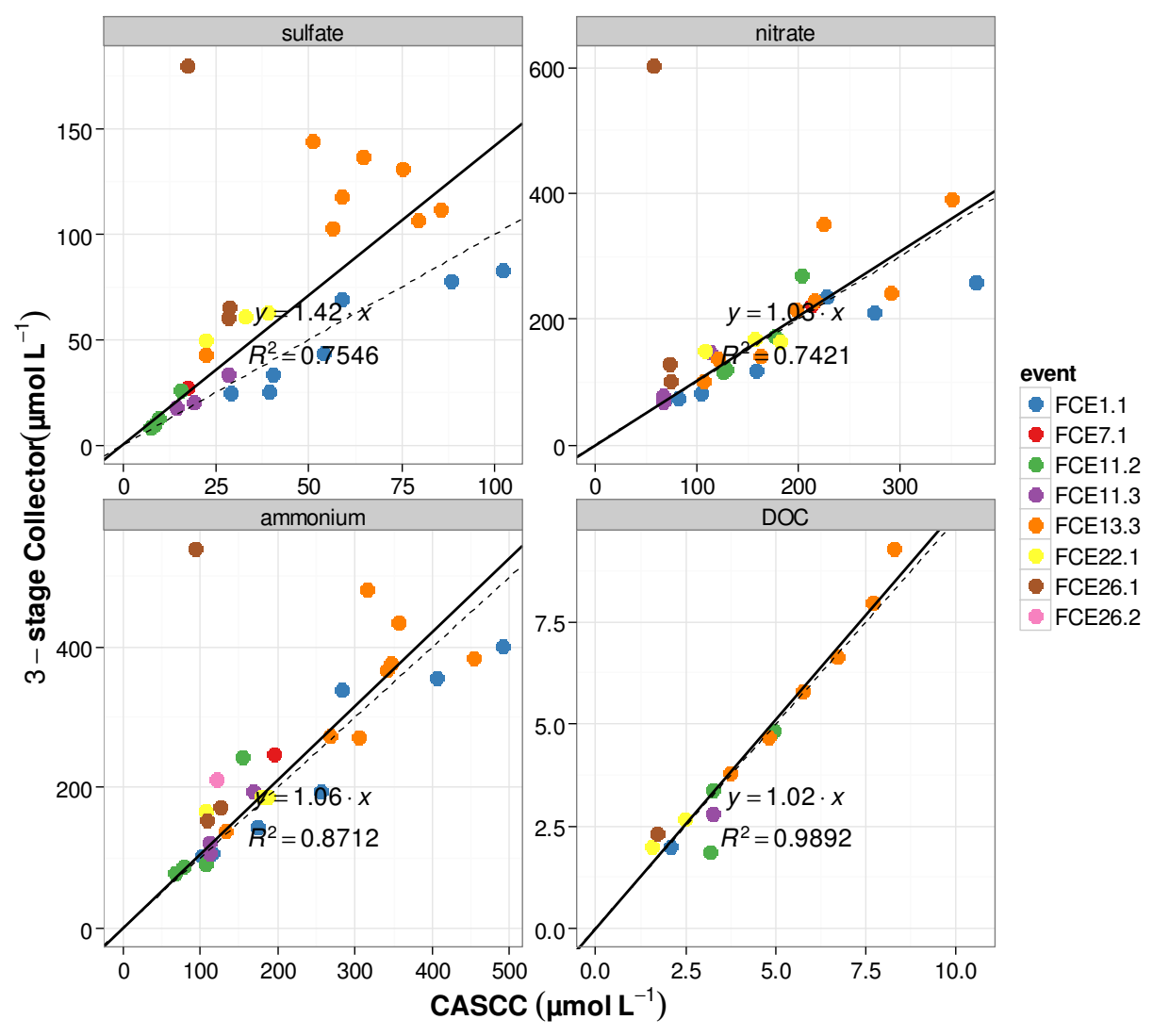

Figure S3: Comparison of solute concentrations of main cloud water constituents between bulk (CASCC) and 3-stage collector (volume-weighted means). Dashed line is 1:1.

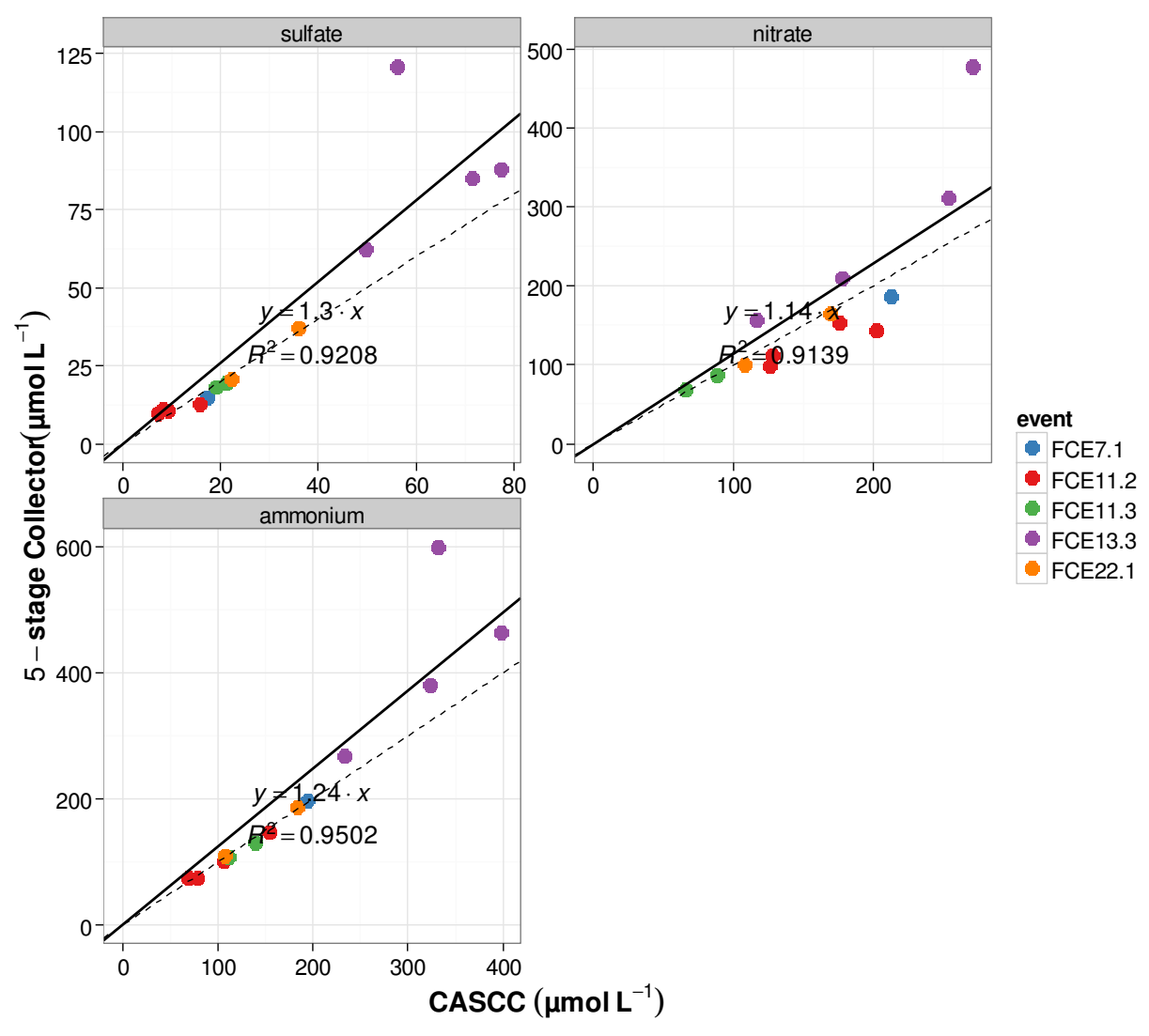

Figure S4: Comparison of solute concentrations of main cloud water constituents between bulk (CASCC) and 5-stage collector (volume-weighted means). Dashed line is 1:1. Note that DOC was not available for most of the 5-stage samples. 


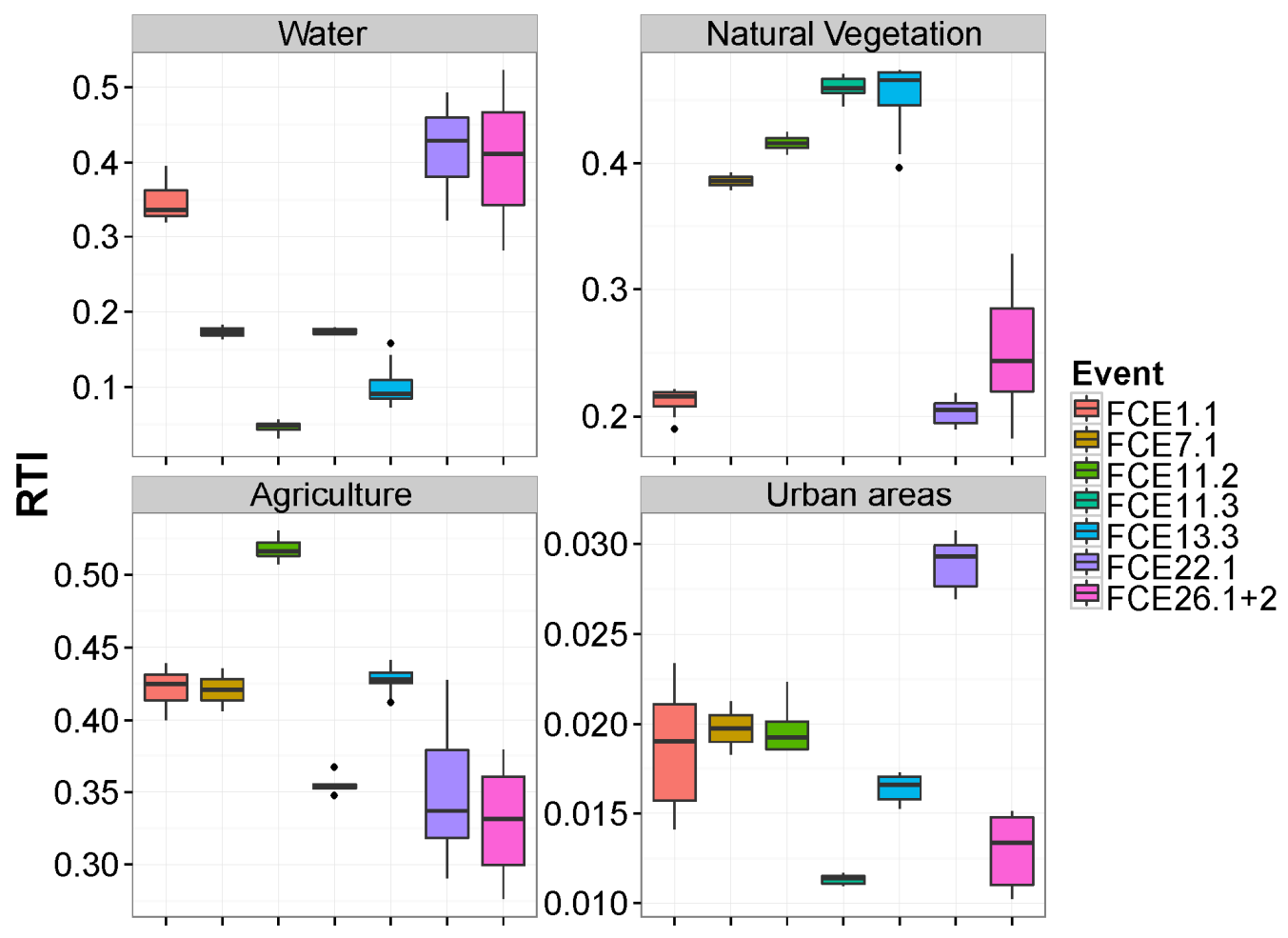

Figure S5: Box-plots of residence time indices (RTIs) for main land cover classes during cloud events. 


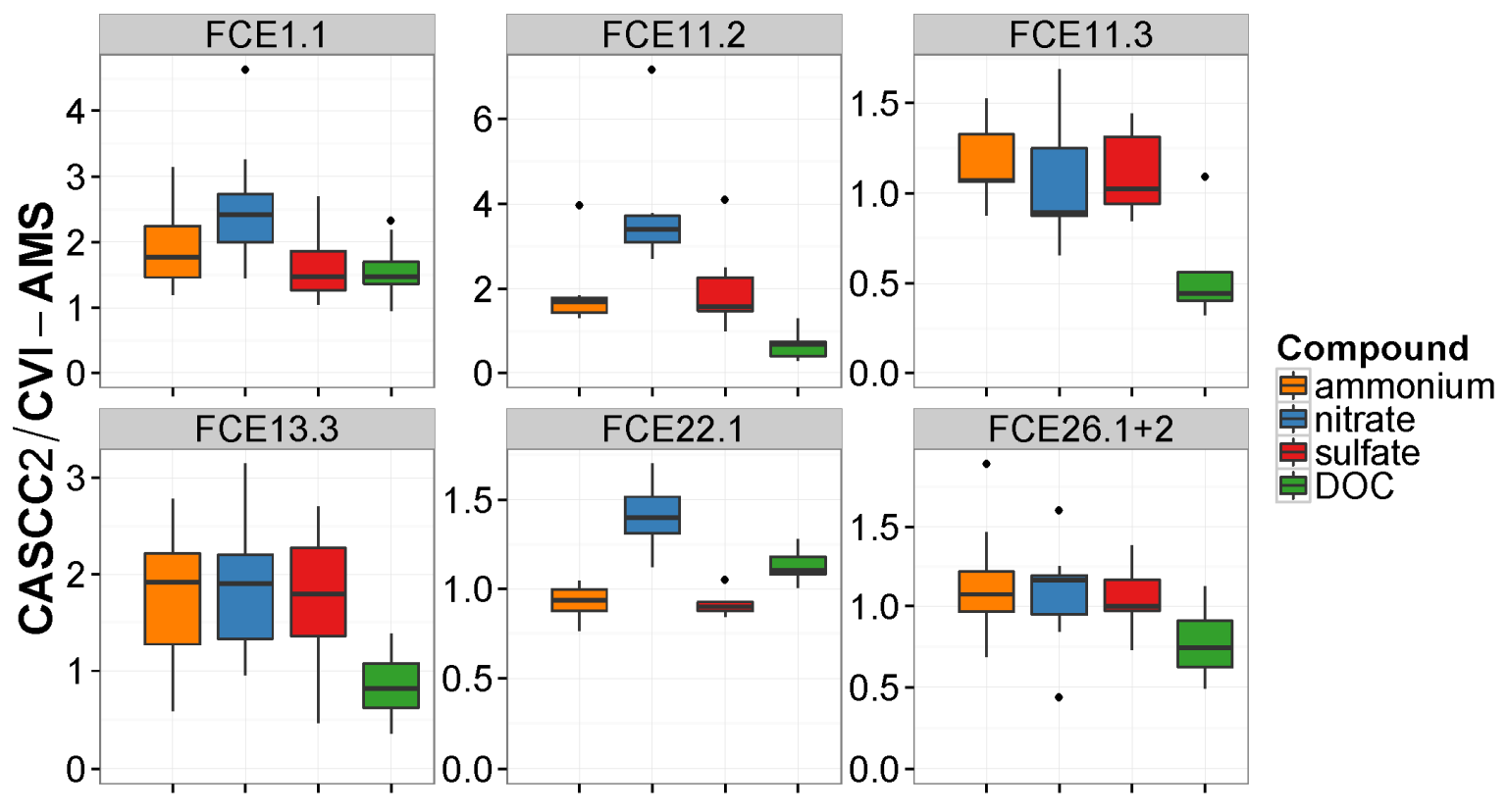

Figure S6: Box-plots of ratios between bulk (CASCC2) and residual particle (CVI-AMS) cloud water loadings for main cloud water constituents. DOC from CVI-AMS calculated as AMS organics divided by 1.8. 


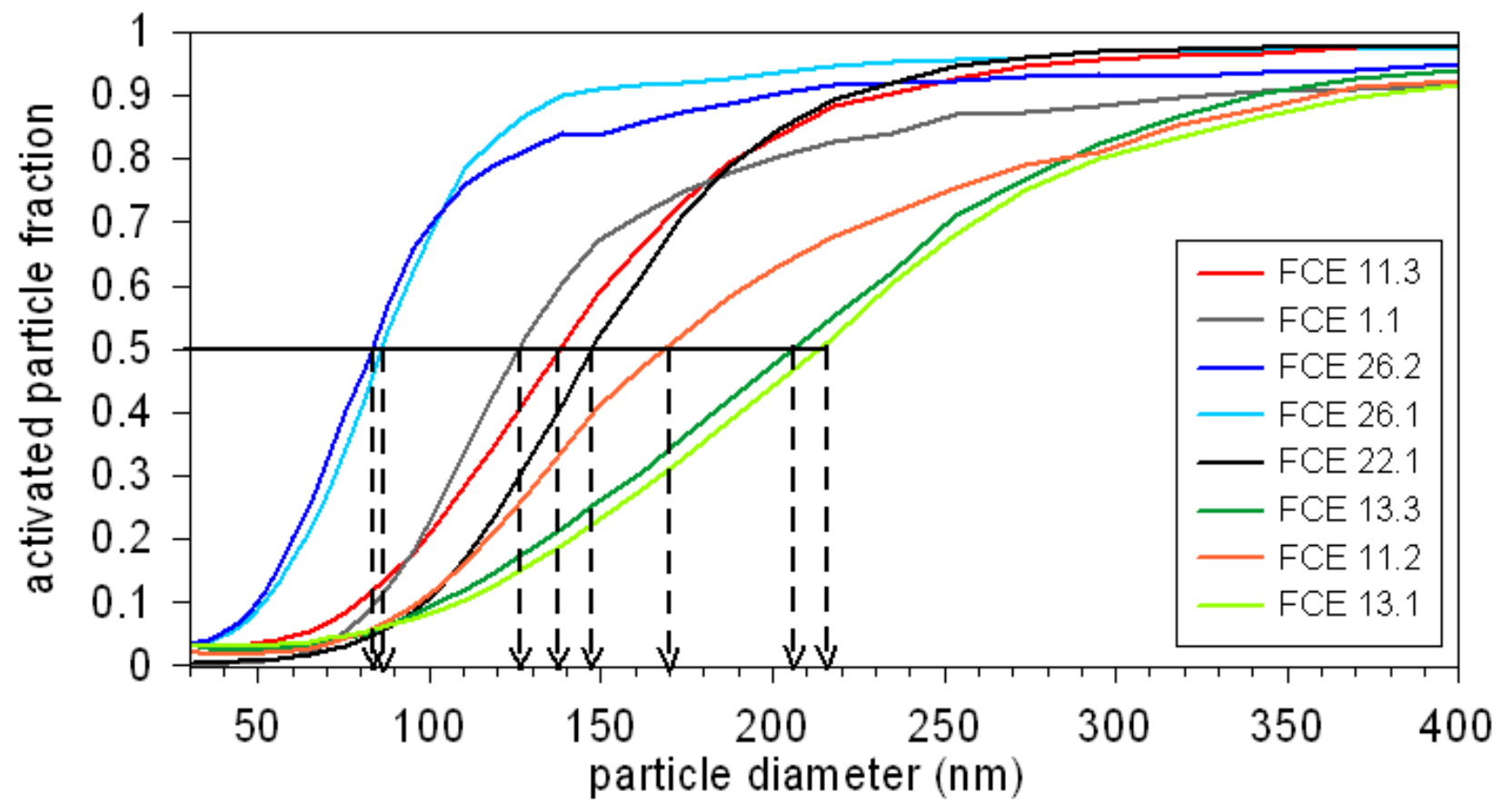

Figure 57: Particle activation curves derived from particle number size distributions of residual particles (CVI inlet) and interstitial particles (INT inlet). 


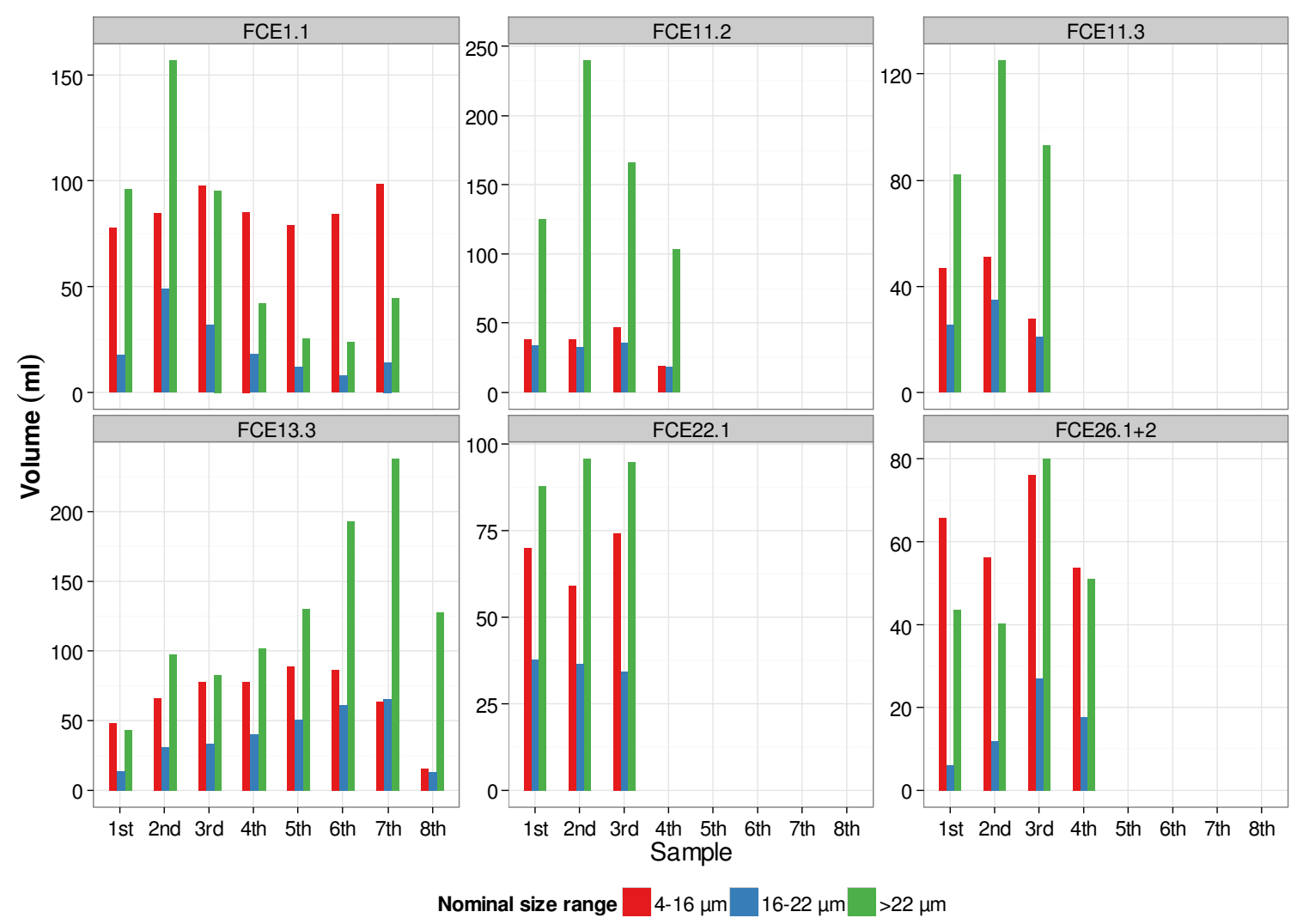

Figure S8: Sampled volumes of cloud water per stage of the 3-stage collector for individual samples. 


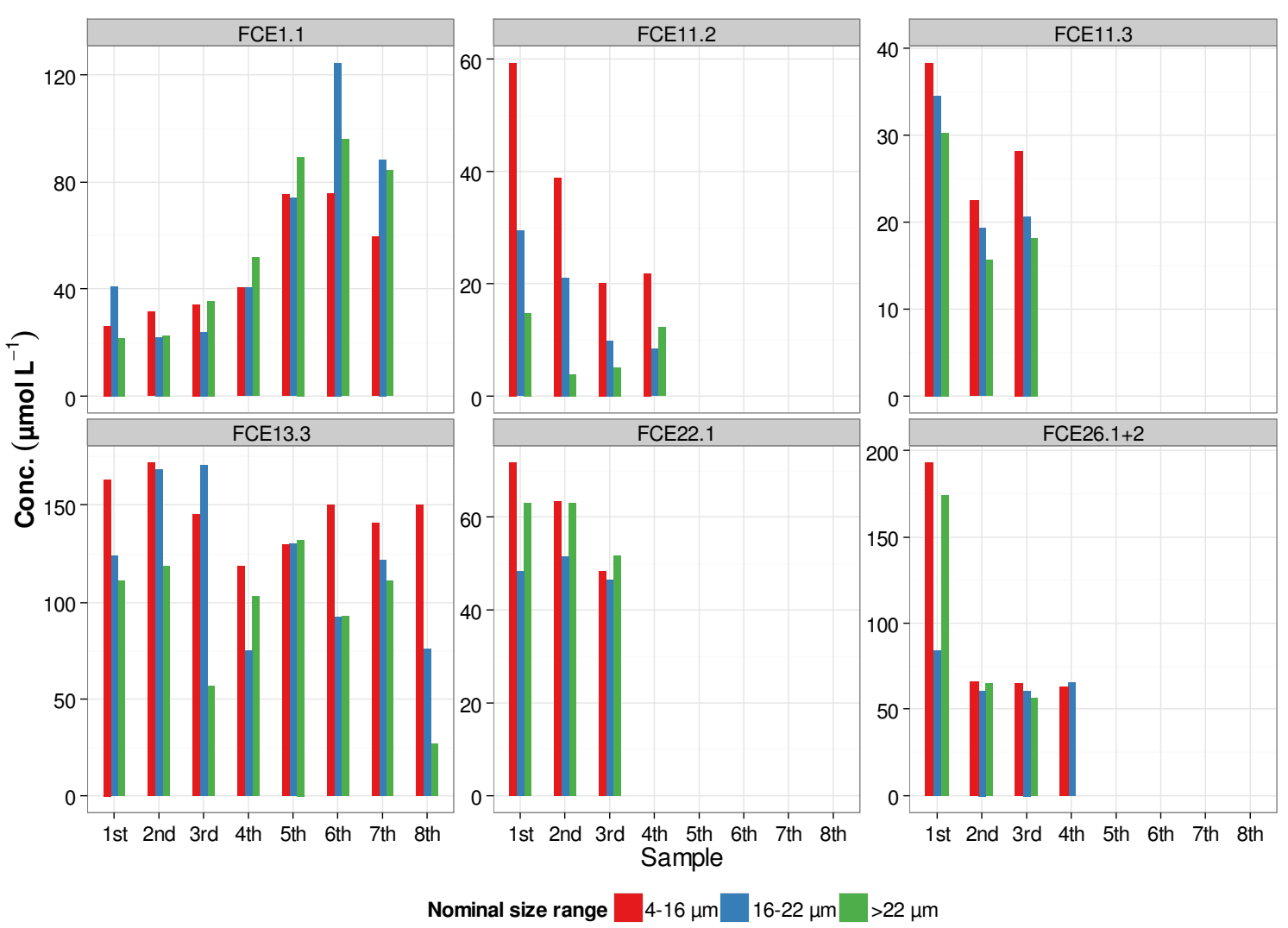

Figure S9: Size-resolved concentrations of sulfate for individual samples from 3-stage cloud water collector.

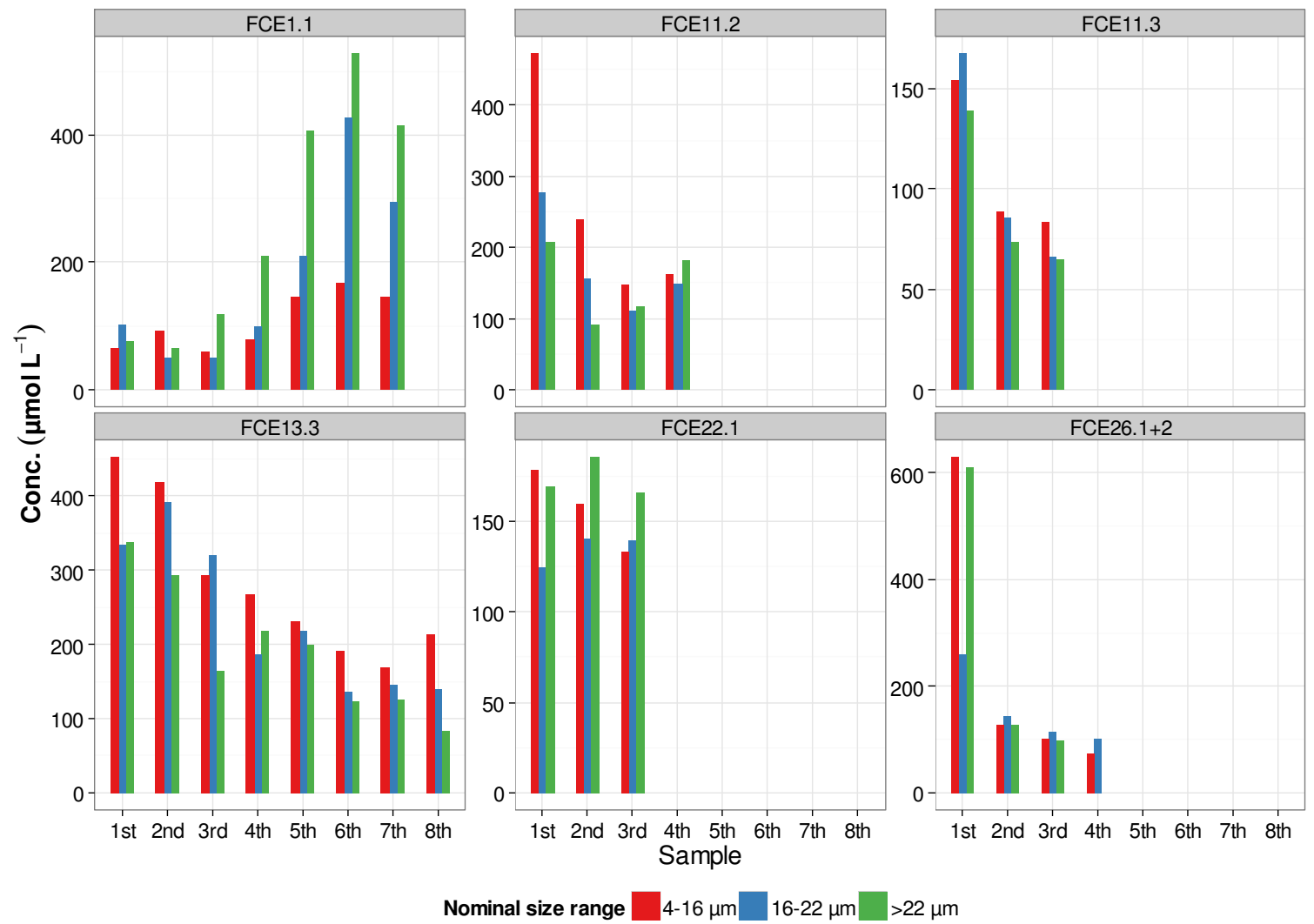

Figure S10: Size-resolved concentrations of nitrate for individual samples from 3-stage cloud water collector. 


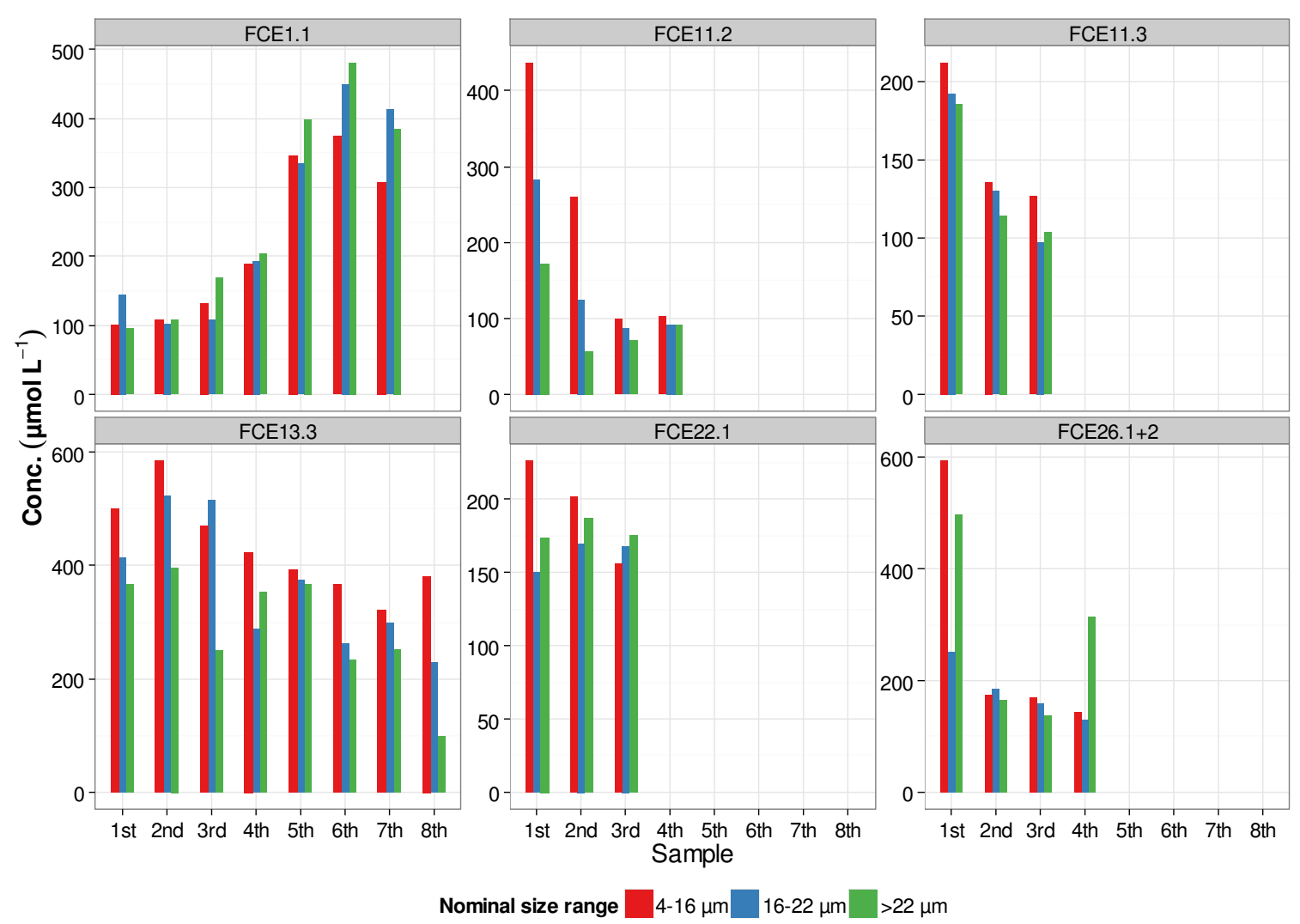

Figure S11: Size-resolved concentrations of ammonium for individual samples from 3-stage cloud water collector. 


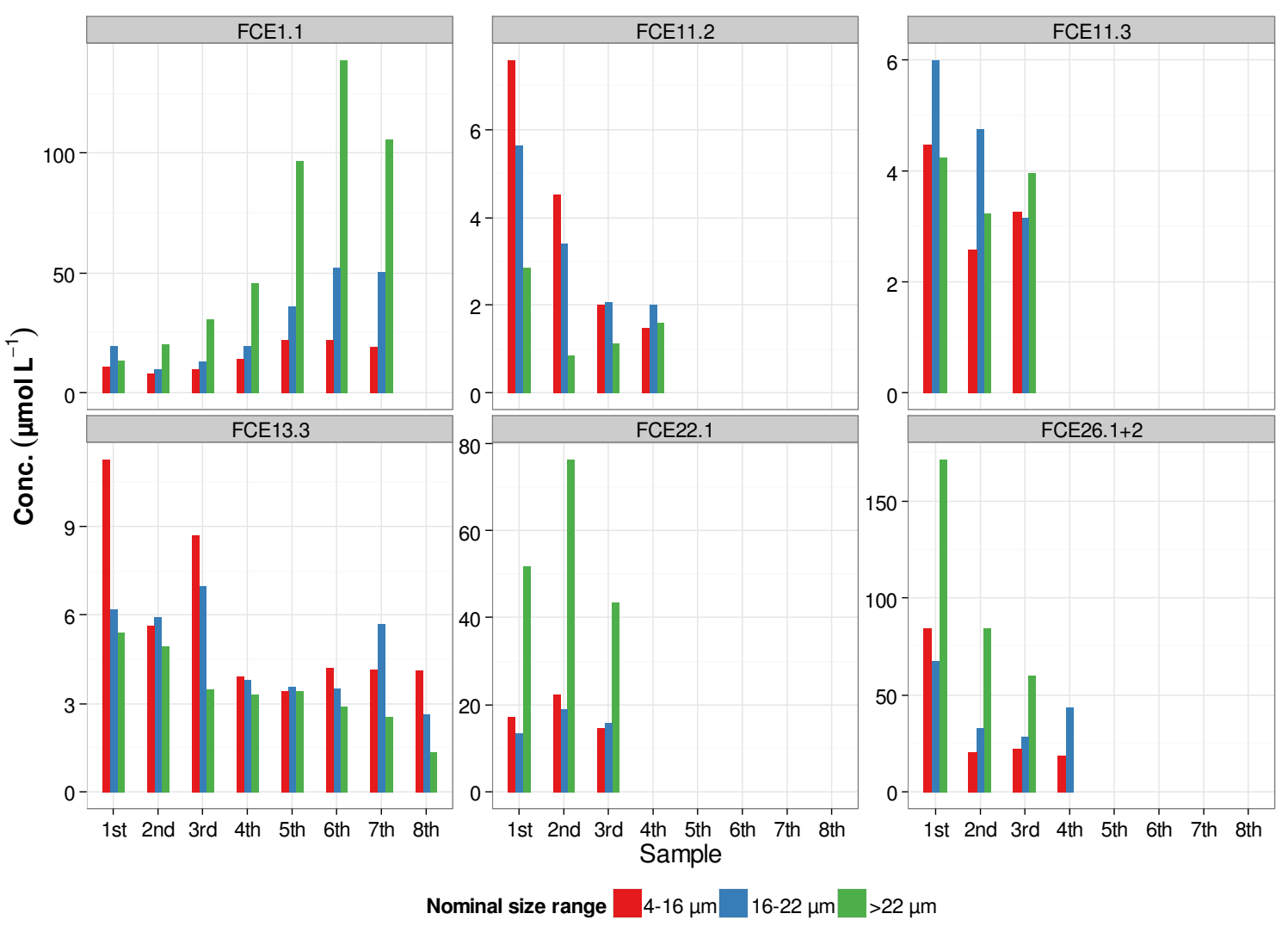

Figure S12: Size-resolved concentrations of chloride for individual samples from 3-stage cloud water collector.

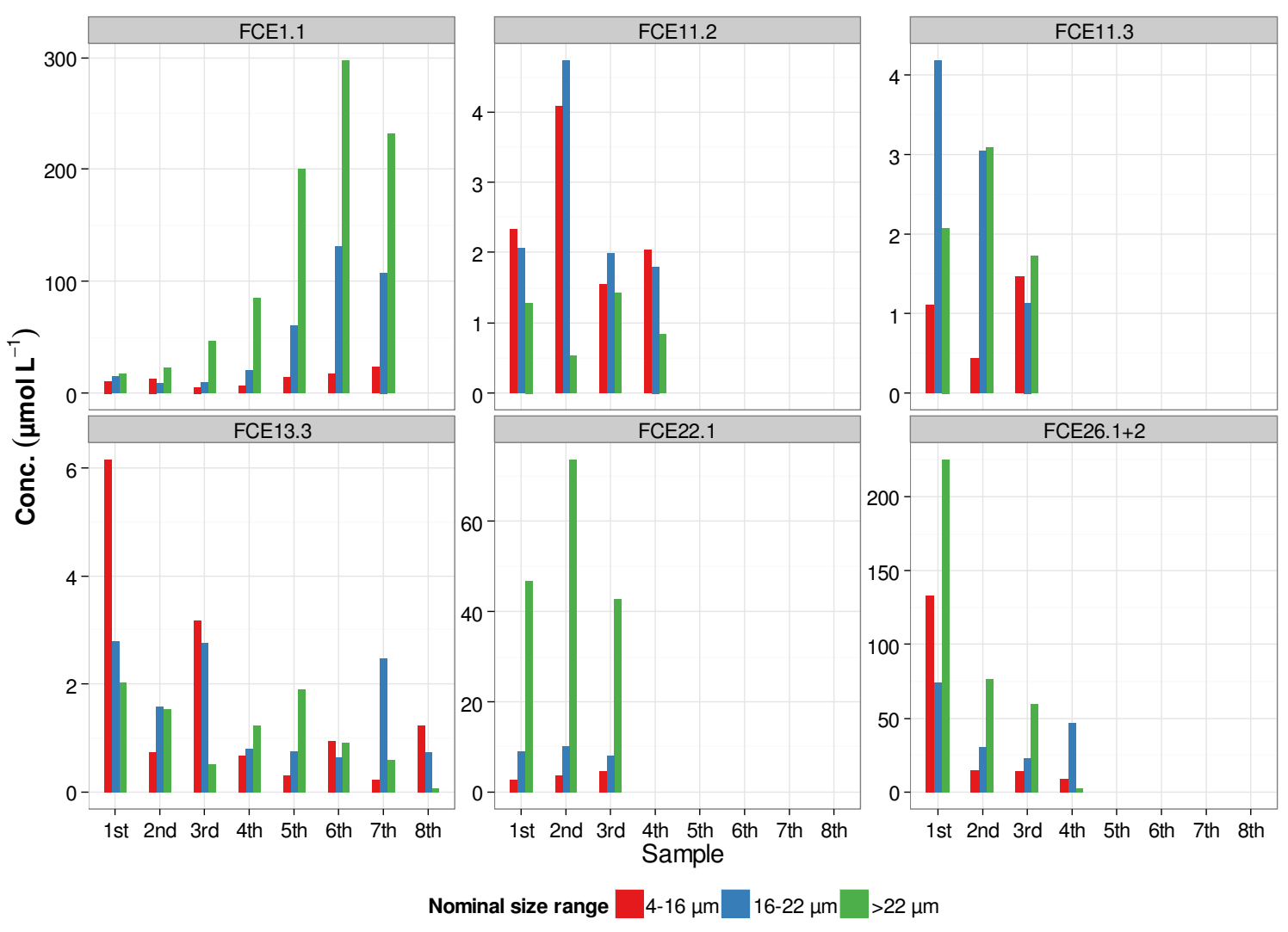

Figure S13: Size-resolved concentrations of sodium for individual samples from 3-stage cloud water collector. 


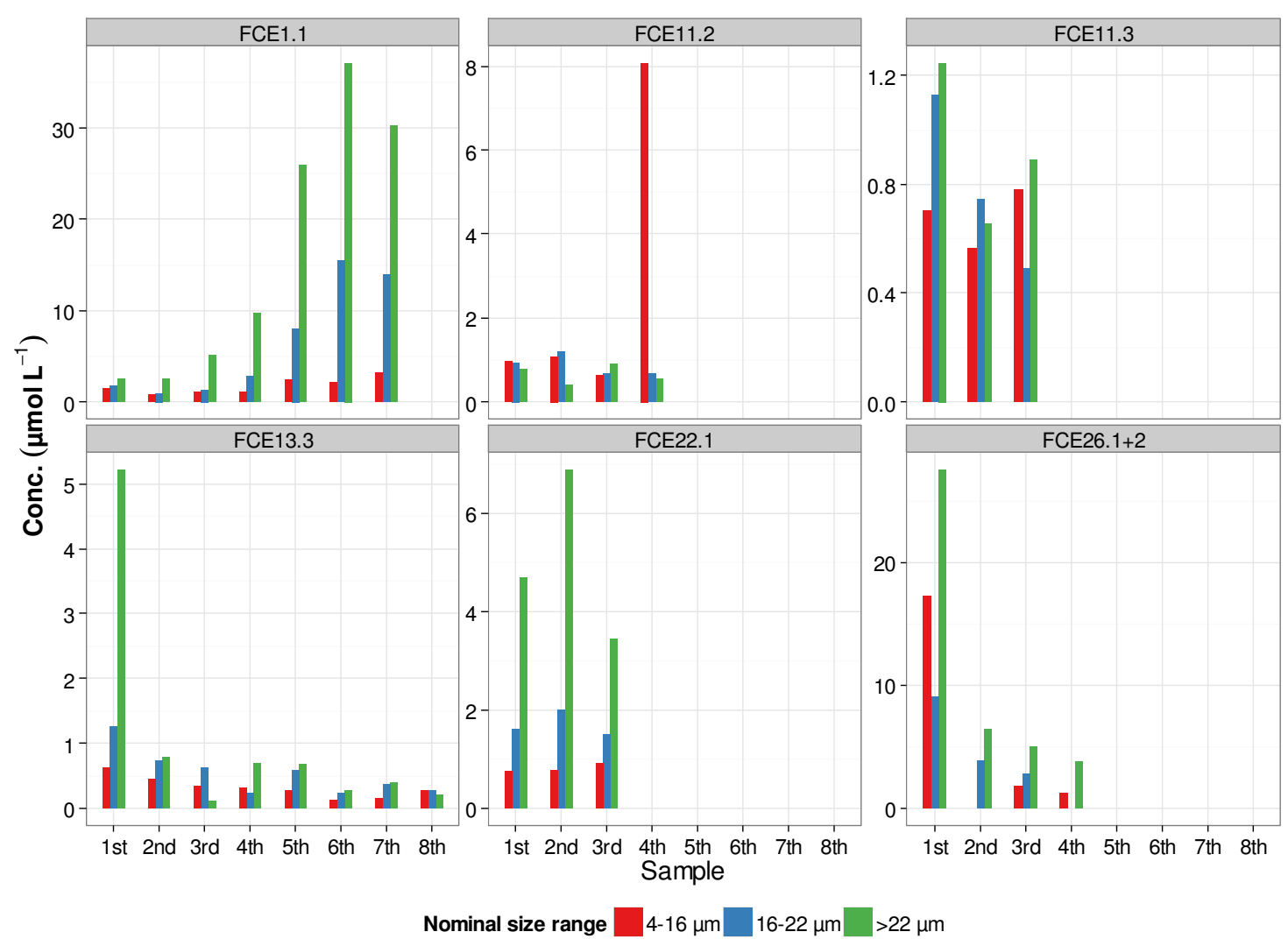

Figure S14: Size-resolved concentrations of magnesium for individual samples from 3-stage cloud water collector.

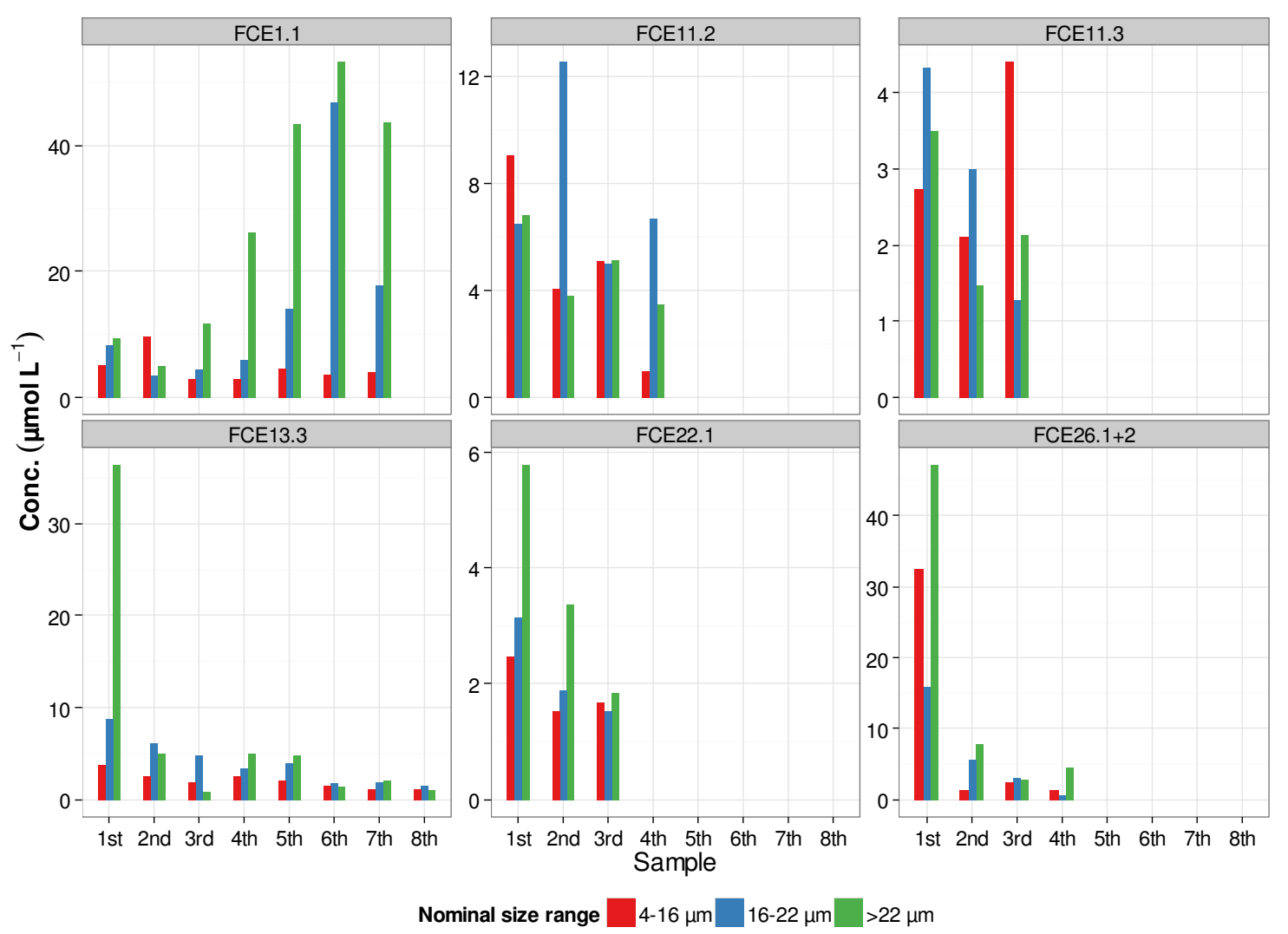

Figure S15: Size-resolved concentrations of calcium for individual samples from 3-stage cloud water collector. 


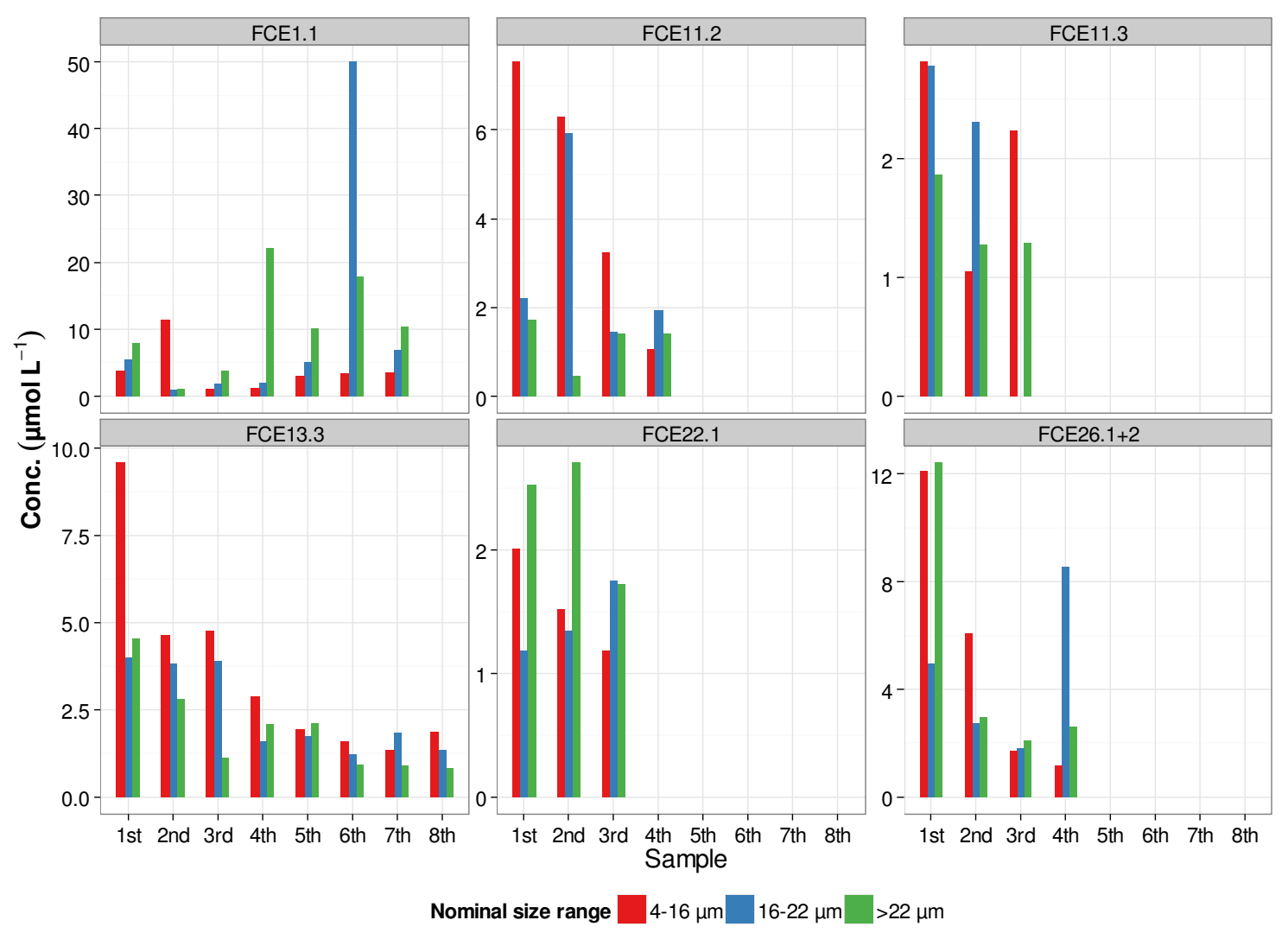

Figure S16: Size-resolved concentrations of potassium for individual samples from 3-stage cloud water collector.

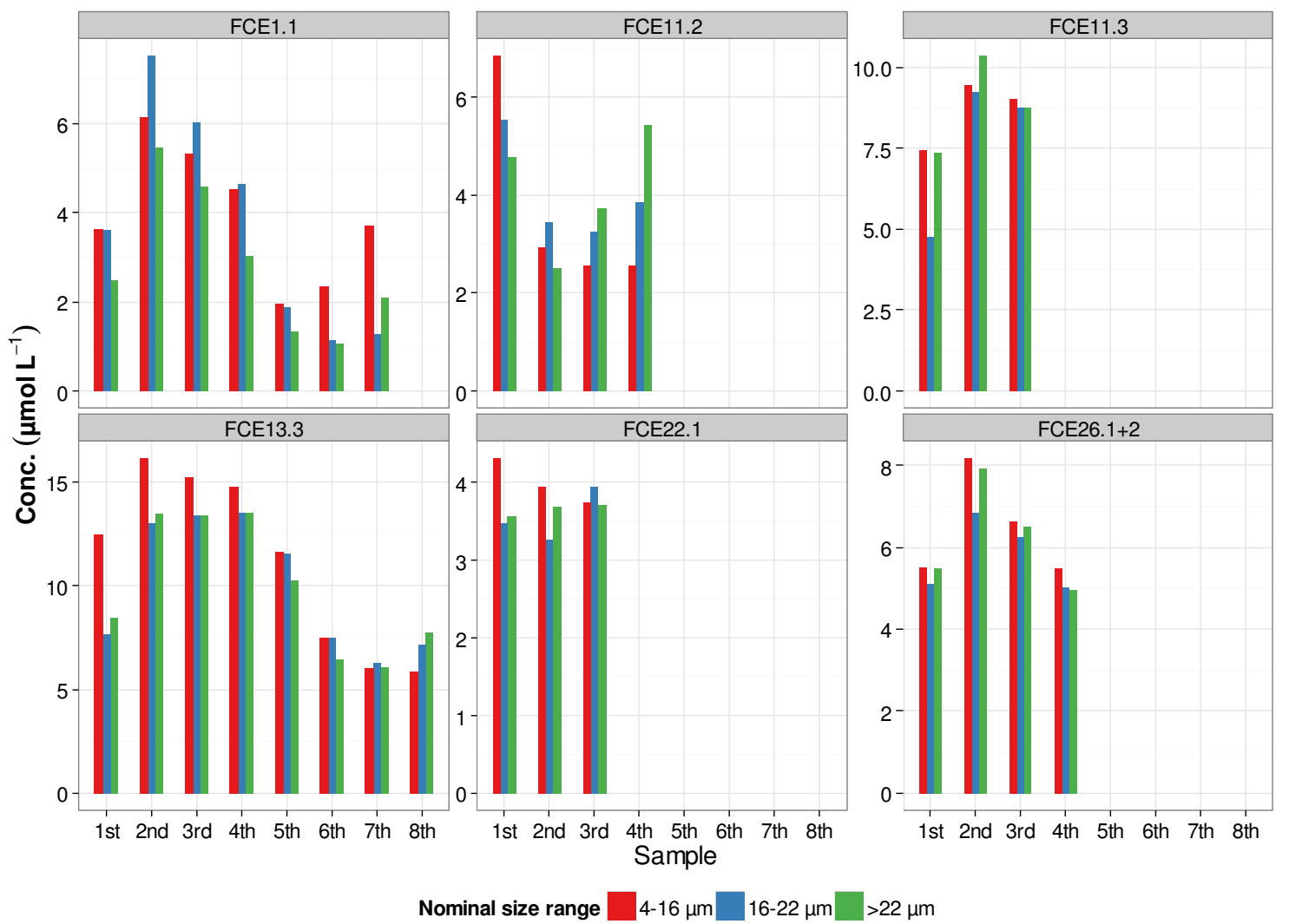

Figure S17: Size-resolved concentrations of $\mathrm{H}_{2} \mathrm{O}_{2}(\mathrm{aq})$ for individual samples from 3-stage cloud water collector. 


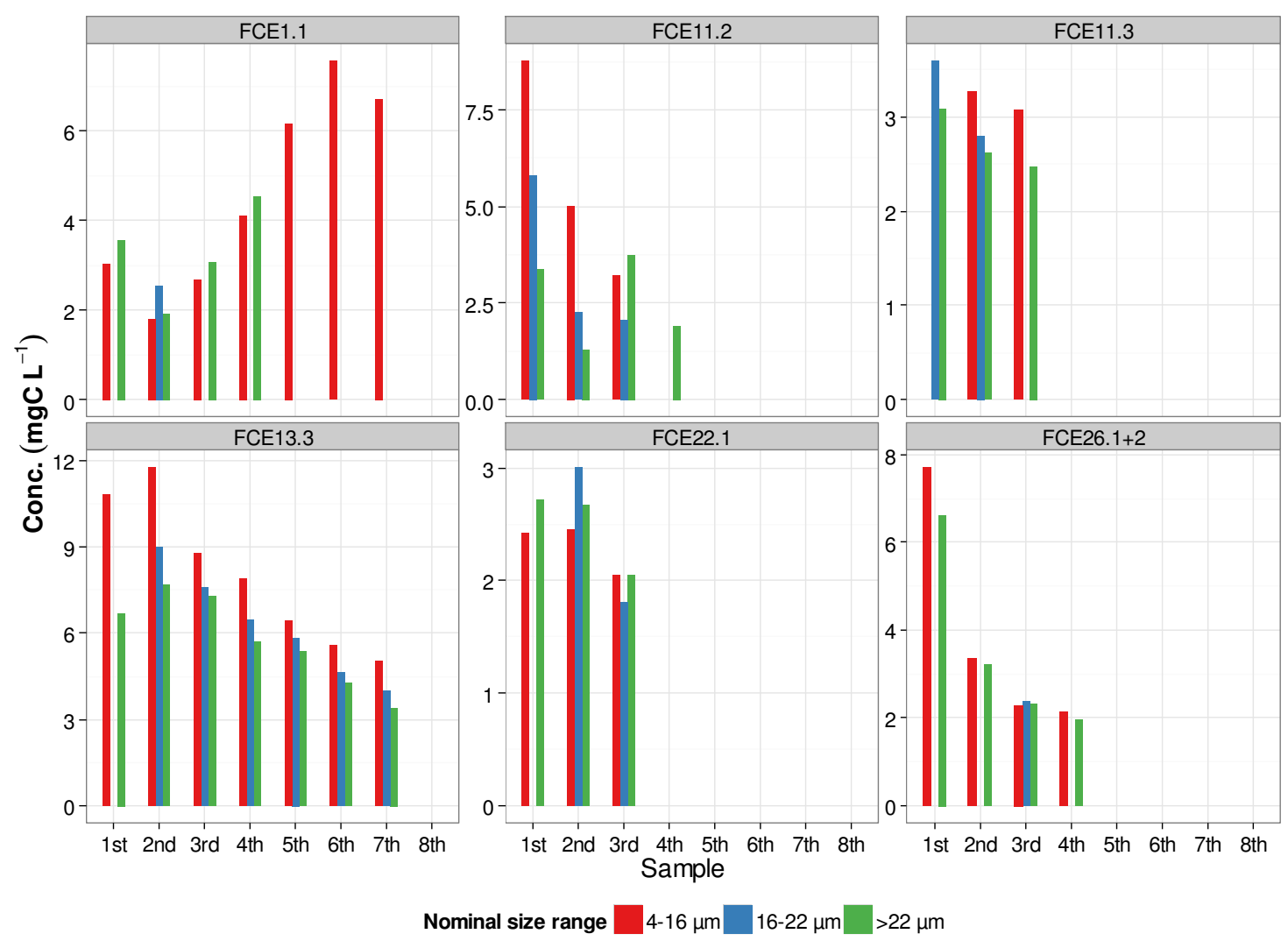

Figure S18: Size-resolved concentrations of DOC for individual samples from 3-stage cloud water collector. 


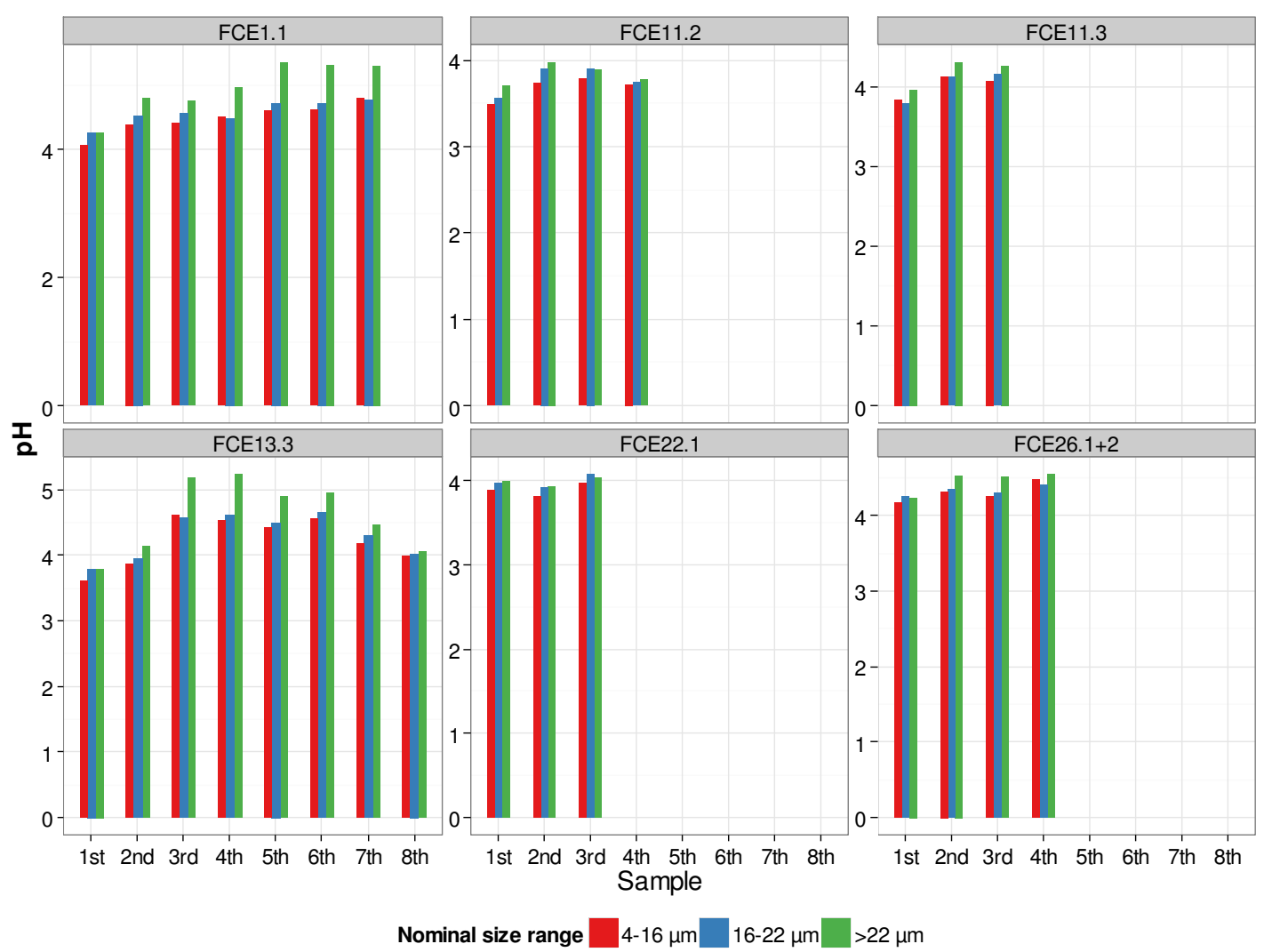

Figure S19: Size-resolved pH values for individual samples from 3-stage cloud water collector. 


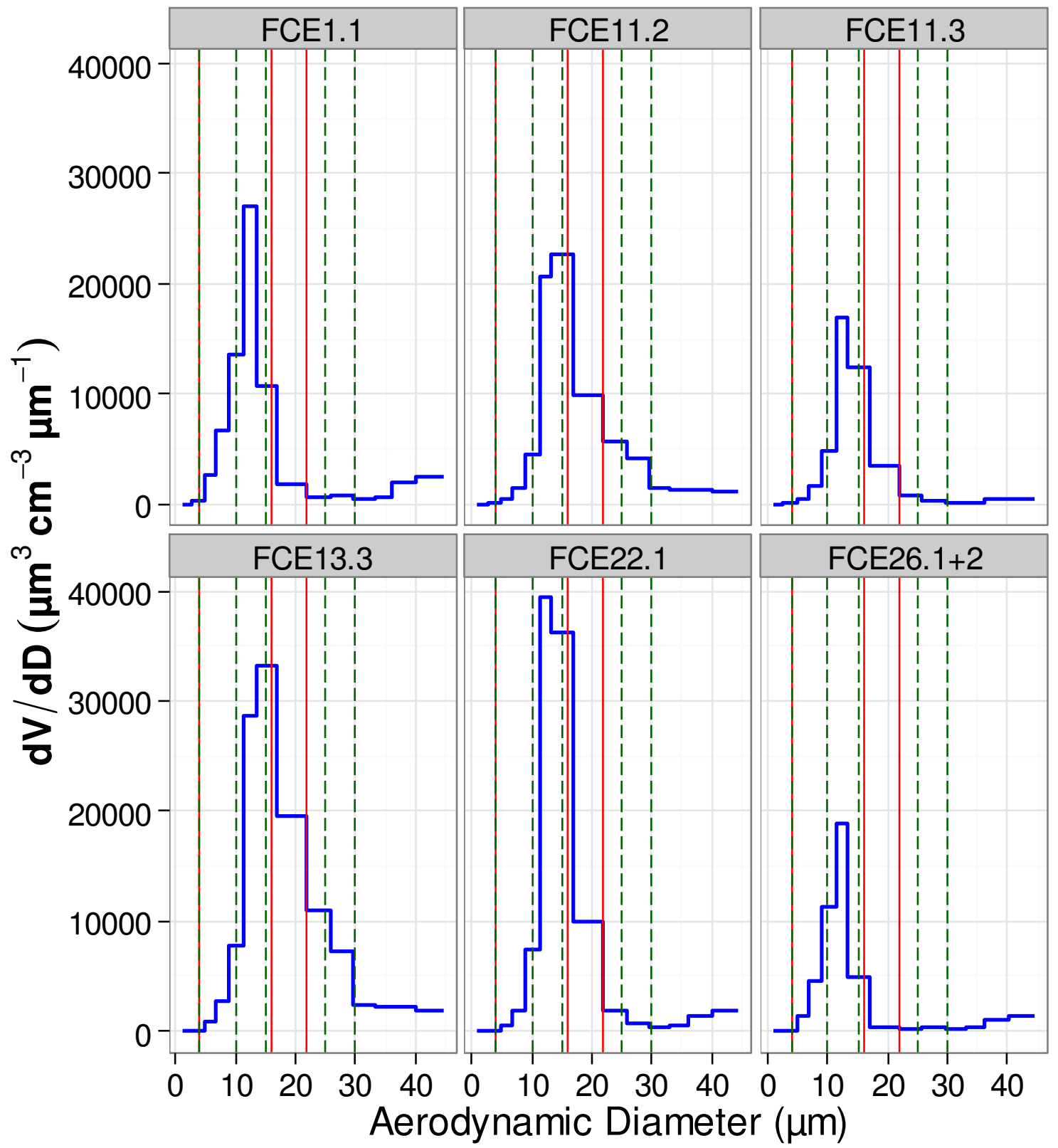

Figure S20: Mean volume size distributions of cloud droplets during main events. Solid red and dashed green lines indicate nominal stage cut-off diameters of 3-stage and 5-stage collector, respectively. 


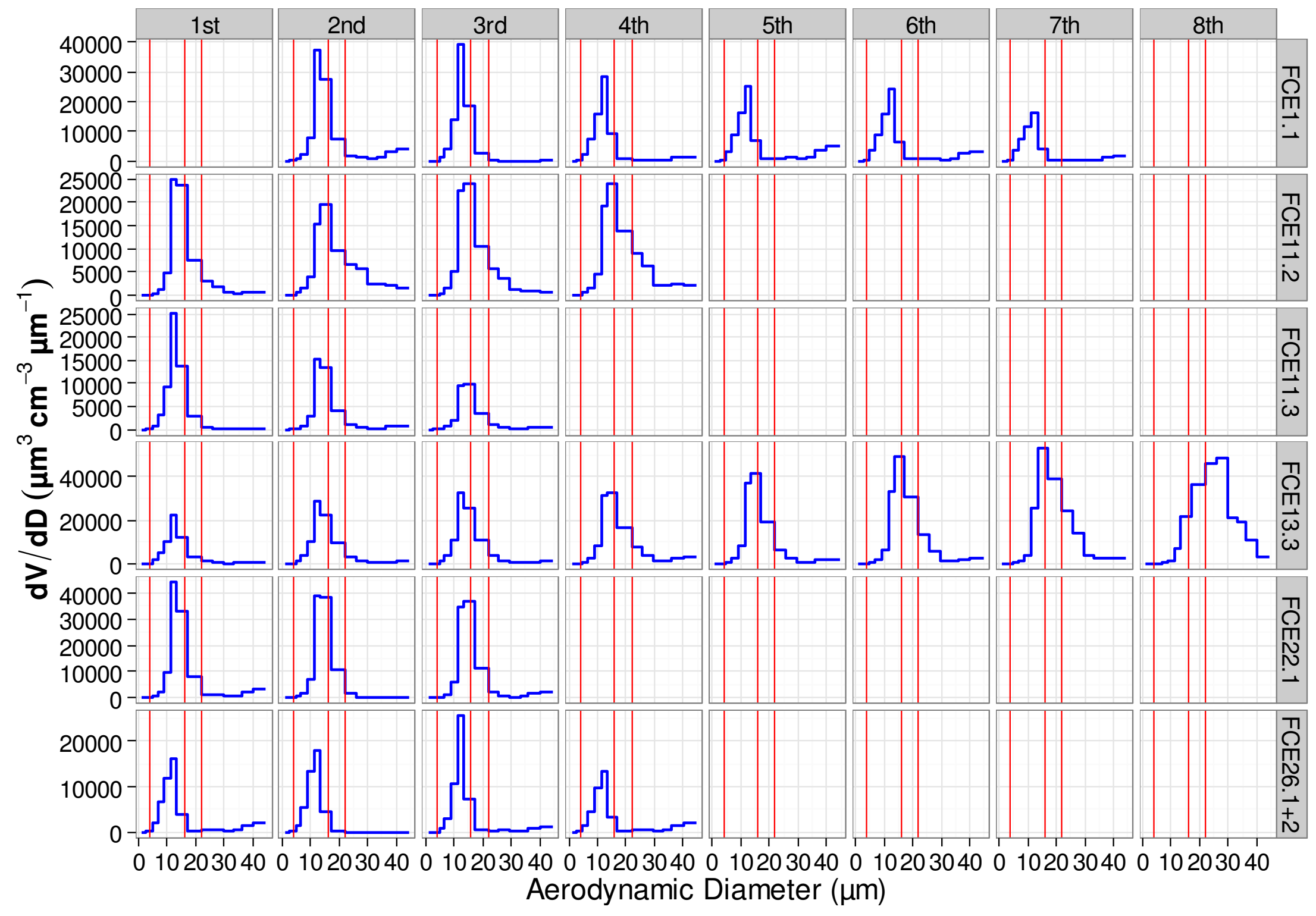

Figure S21: Mean volume size distributions of cloud droplets during individual samples of 3-stage collector. Solid red lines indicate nominal stage cut-off diameters. 


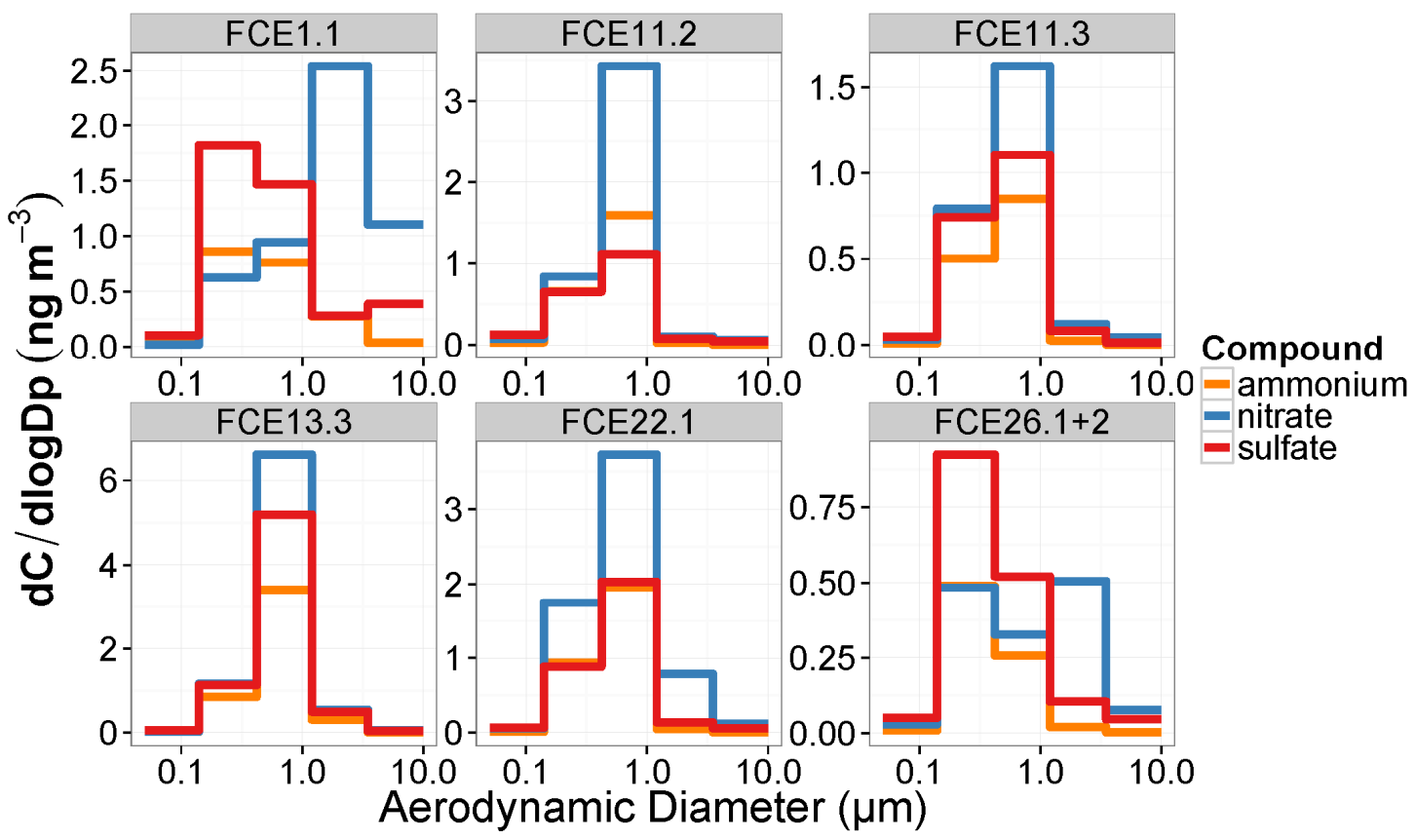

Figure S22: Size distributions of main inorganic ions at upwind site, obtained from 5-stage Berner impactor.

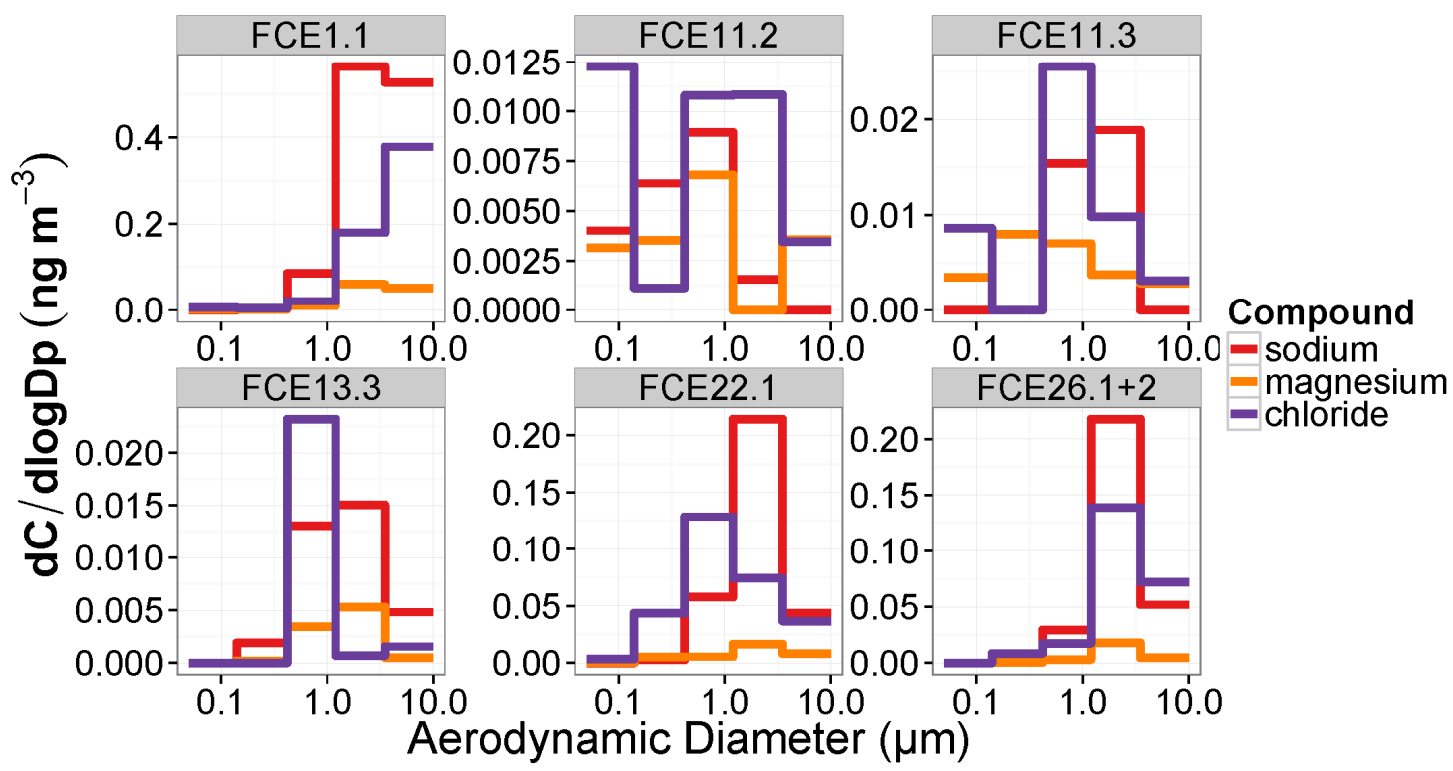

Figure S23: Size distributions of minor inorganic ions at upwind site, obtained from 5-stage Berner impactor. 


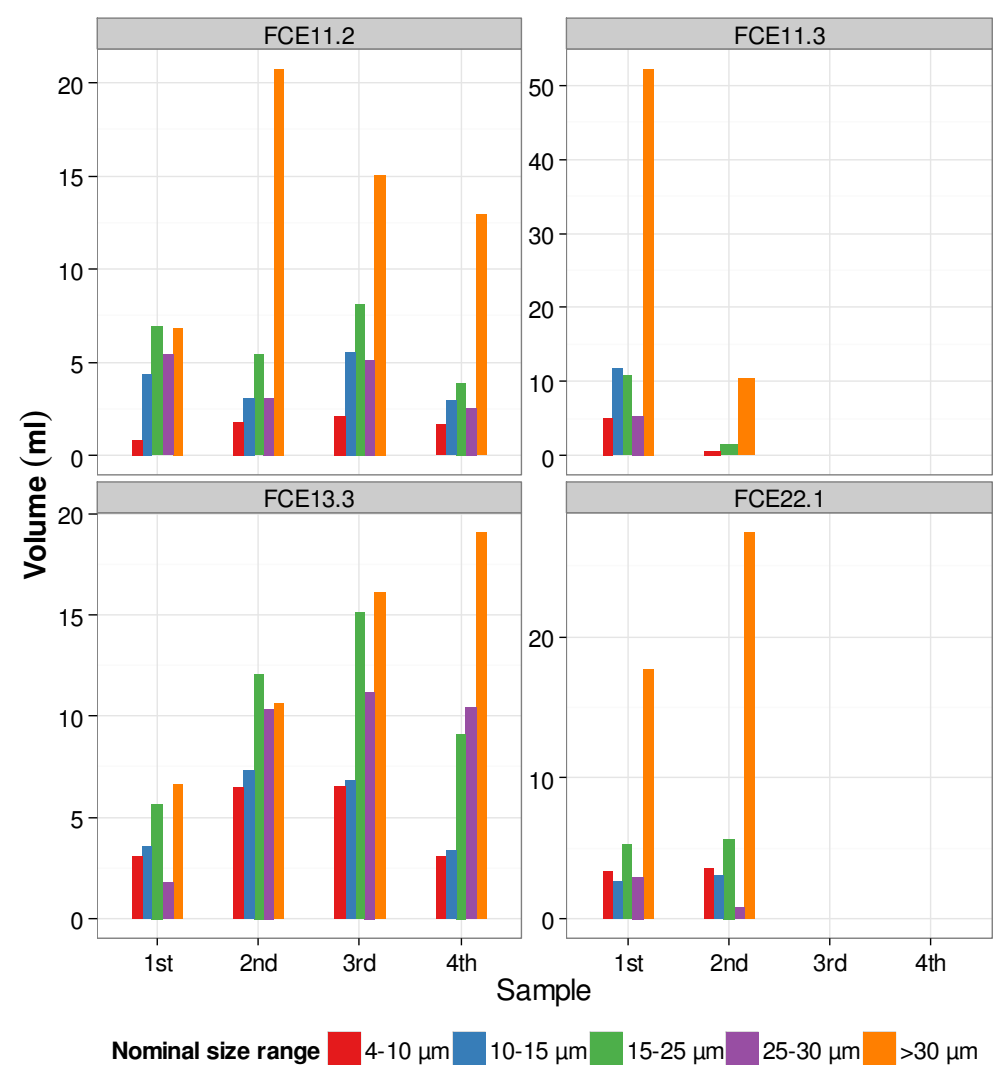

Figure S24: Sampled volumes of cloud water per stage of the 5-stage collector for individual samples. 


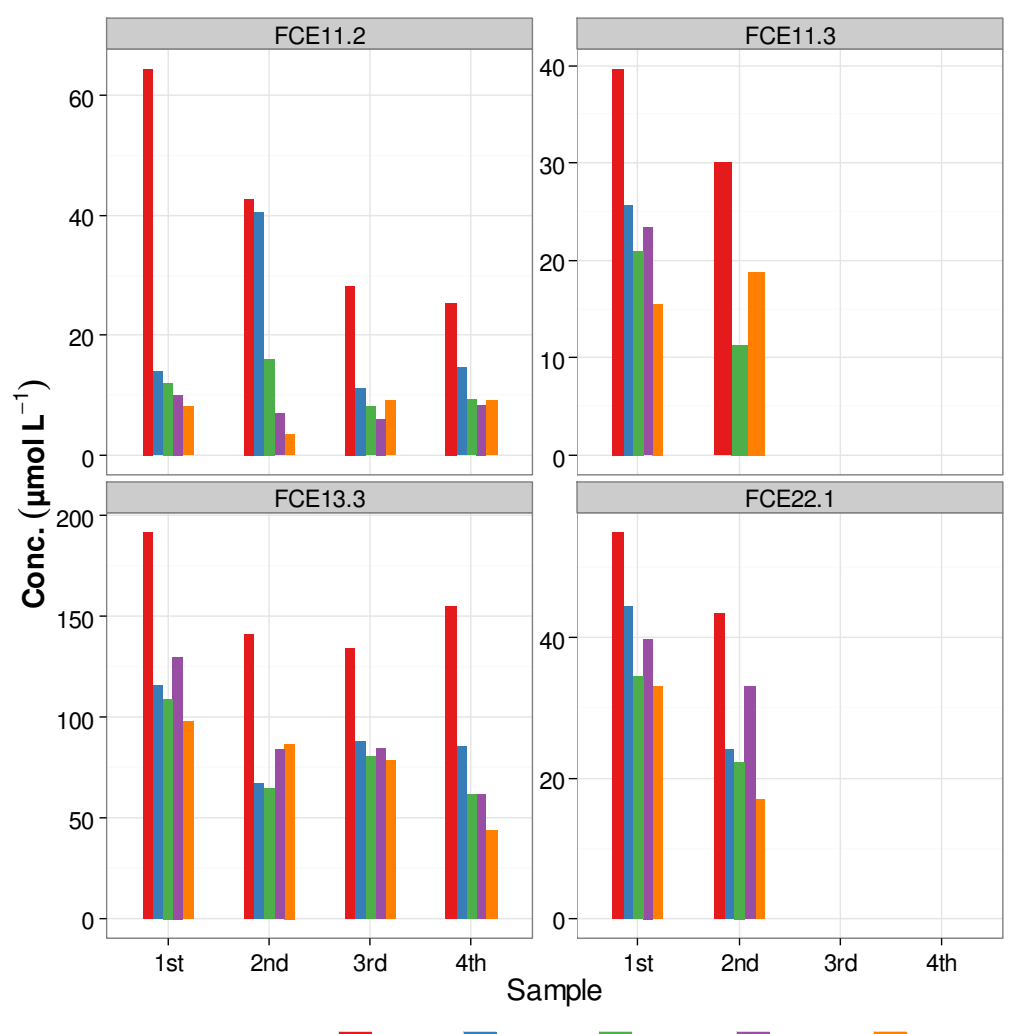

Figure S25: Size-resolved concentrations of sulfate for individual samples from 5-stage cloud water collector.

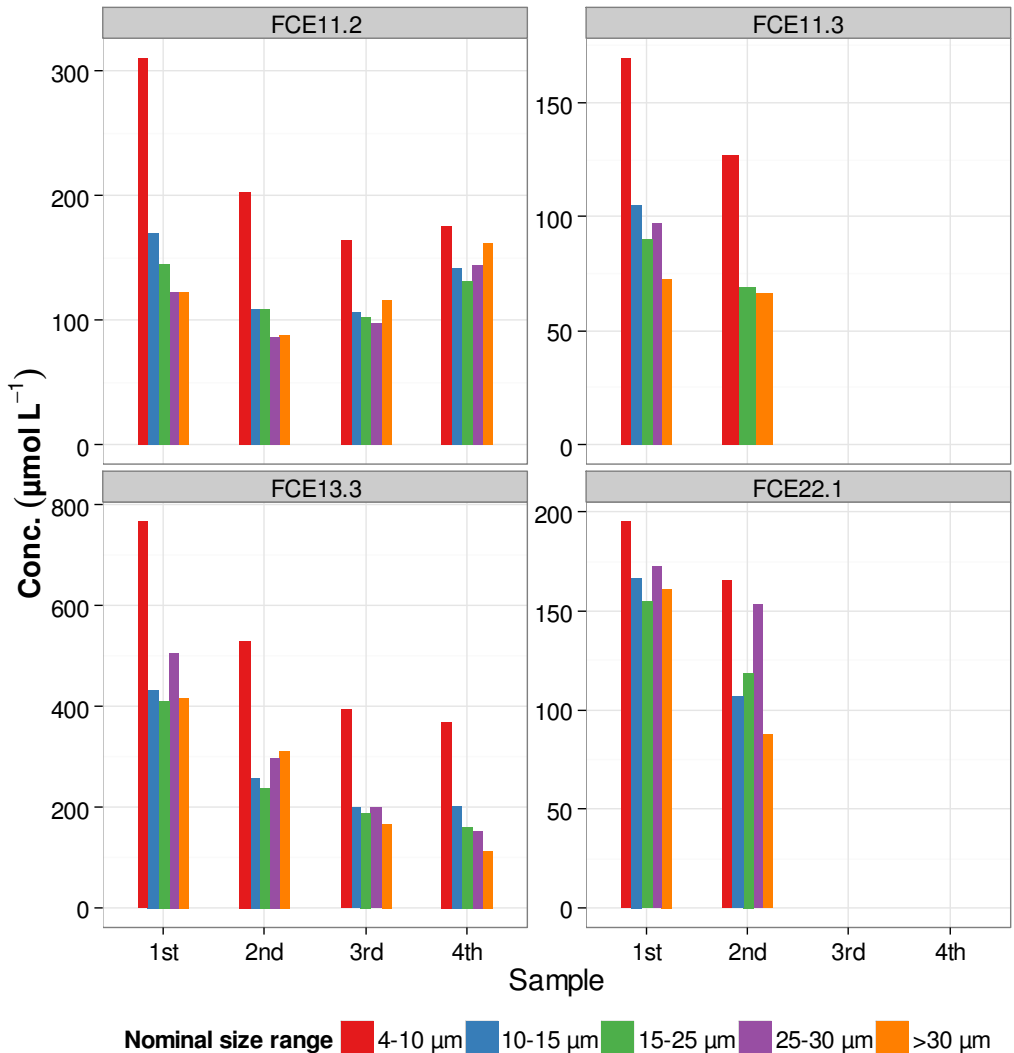

Figure S26: Size-resolved concentrations of nitrate for individual samples from 5-stage cloud water collector. 


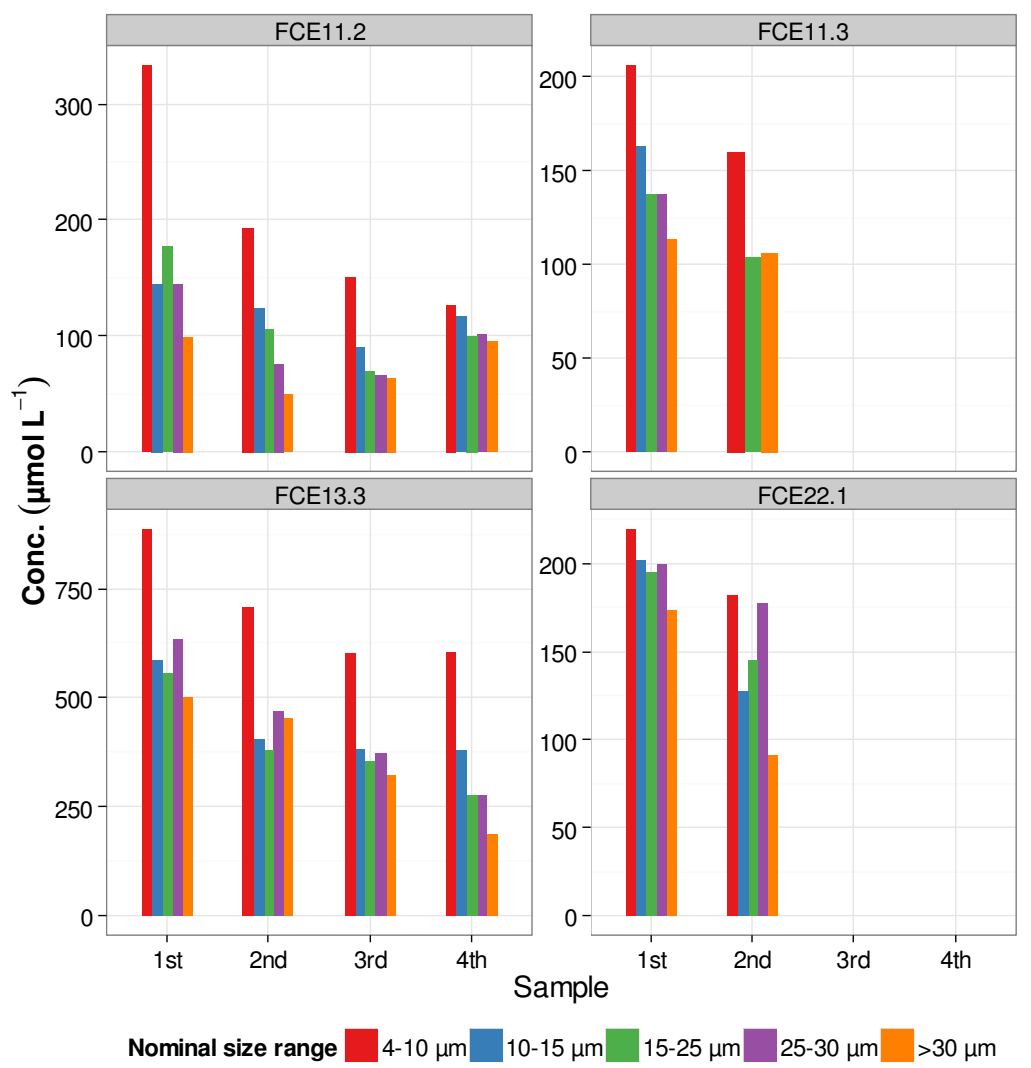

Figure S27: Size-resolved concentrations of ammonium for individual samples from 5-stage cloud water collector.

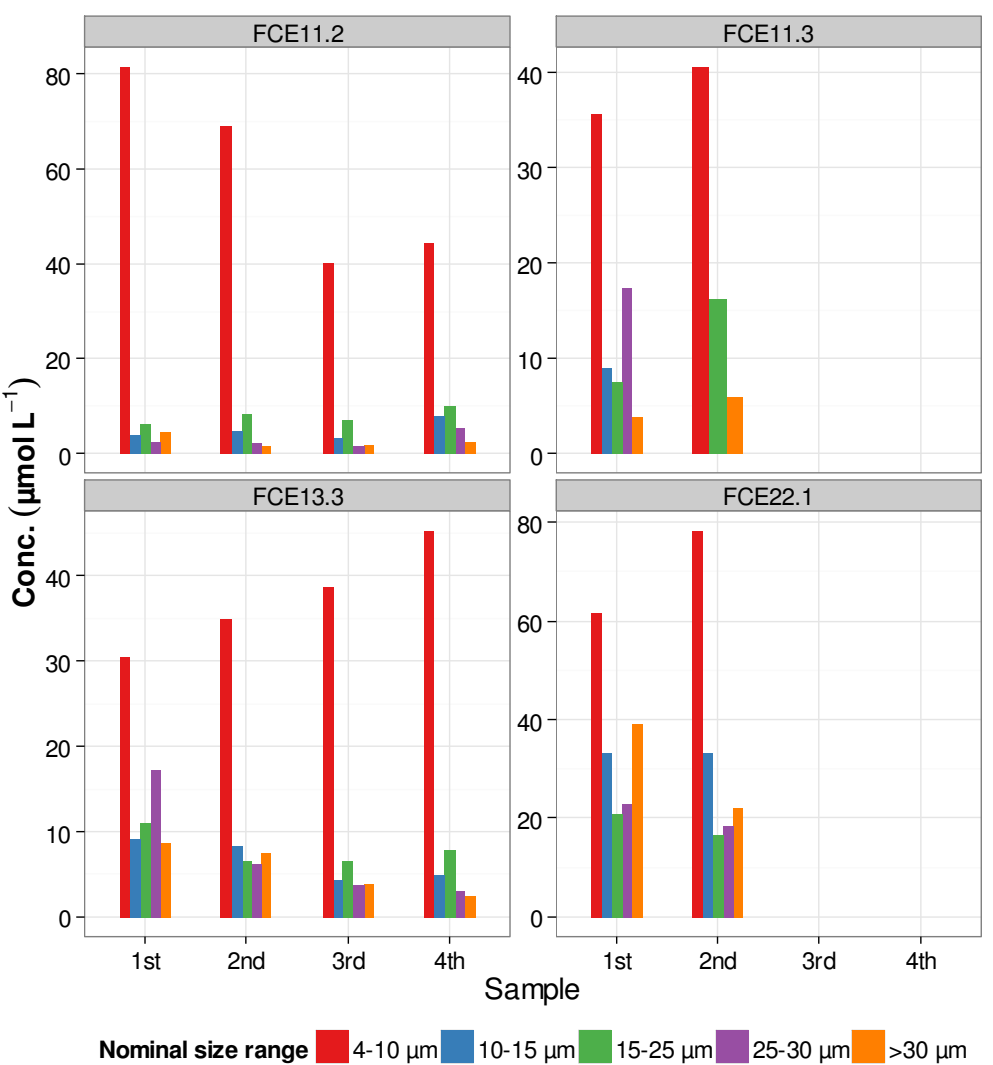

Figure S28: Size-resolved concentrations of chloride for individual samples from 5-stage cloud water collector. 


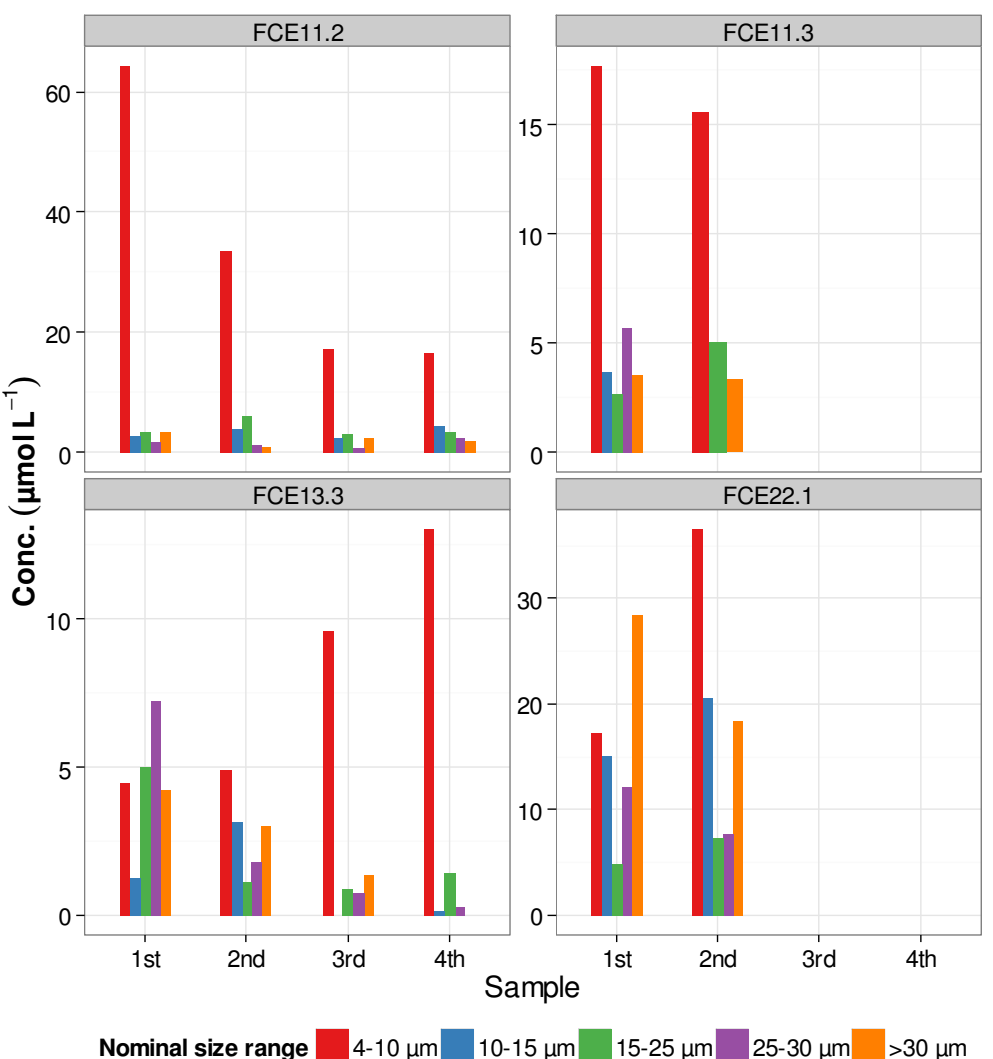

Figure S29: Size-resolved concentrations of sodium for individual samples from 5 -stage cloud water collector.

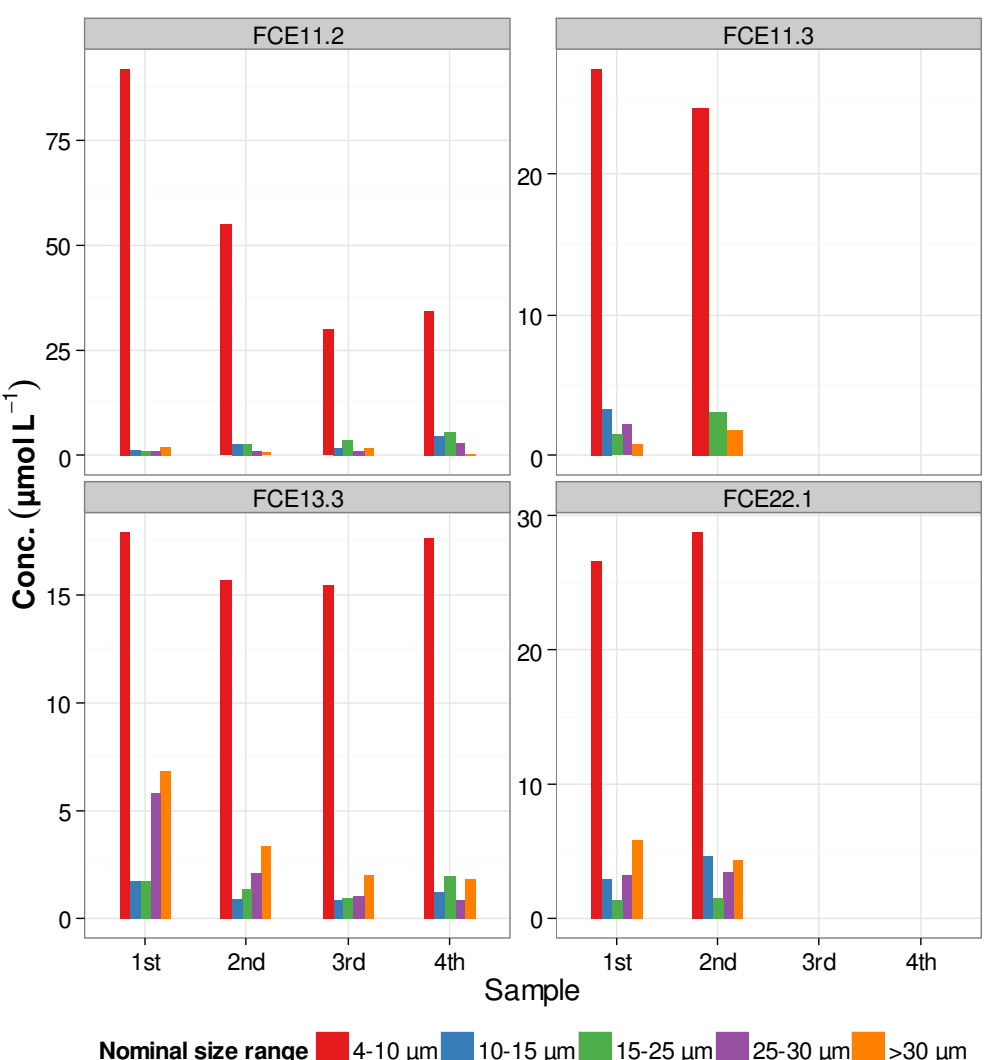

Figure S30: Size-resolved concentrations of magnesium for individual samples from 5-stage cloud water collector. 


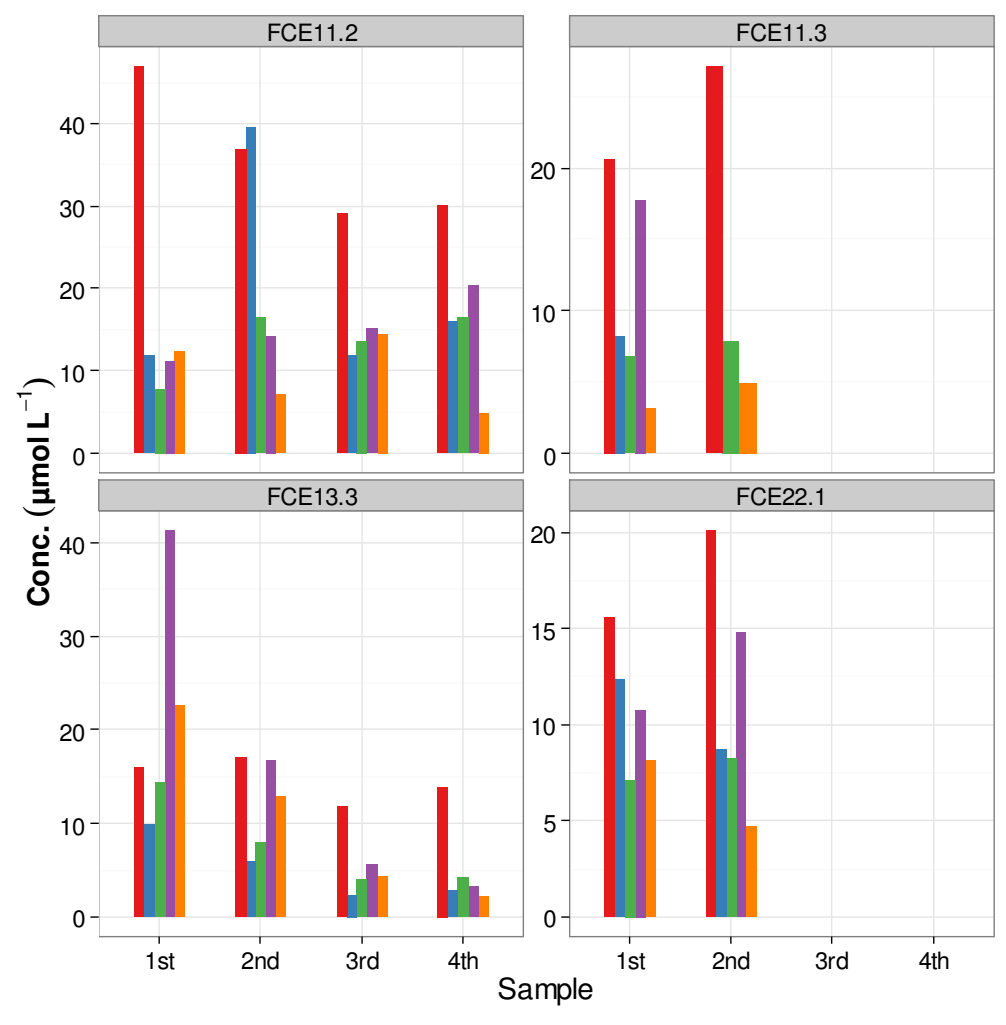

Figure S31: Size-resolved concentrations of calcium for individual samples from 5-stage cloud water collector.

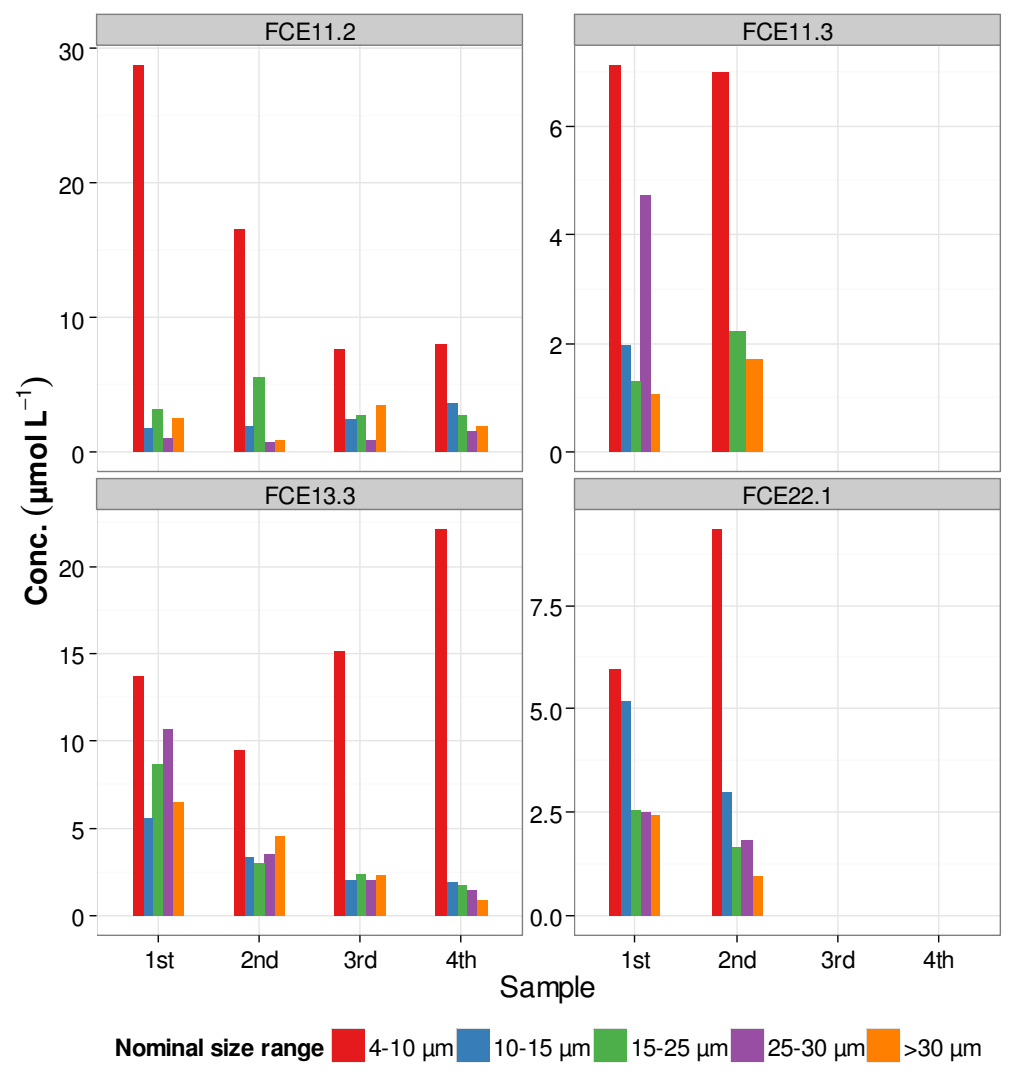

Figure S32: Size-resolved concentrations of potassium for individual samples from 5-stage cloud water collector. 


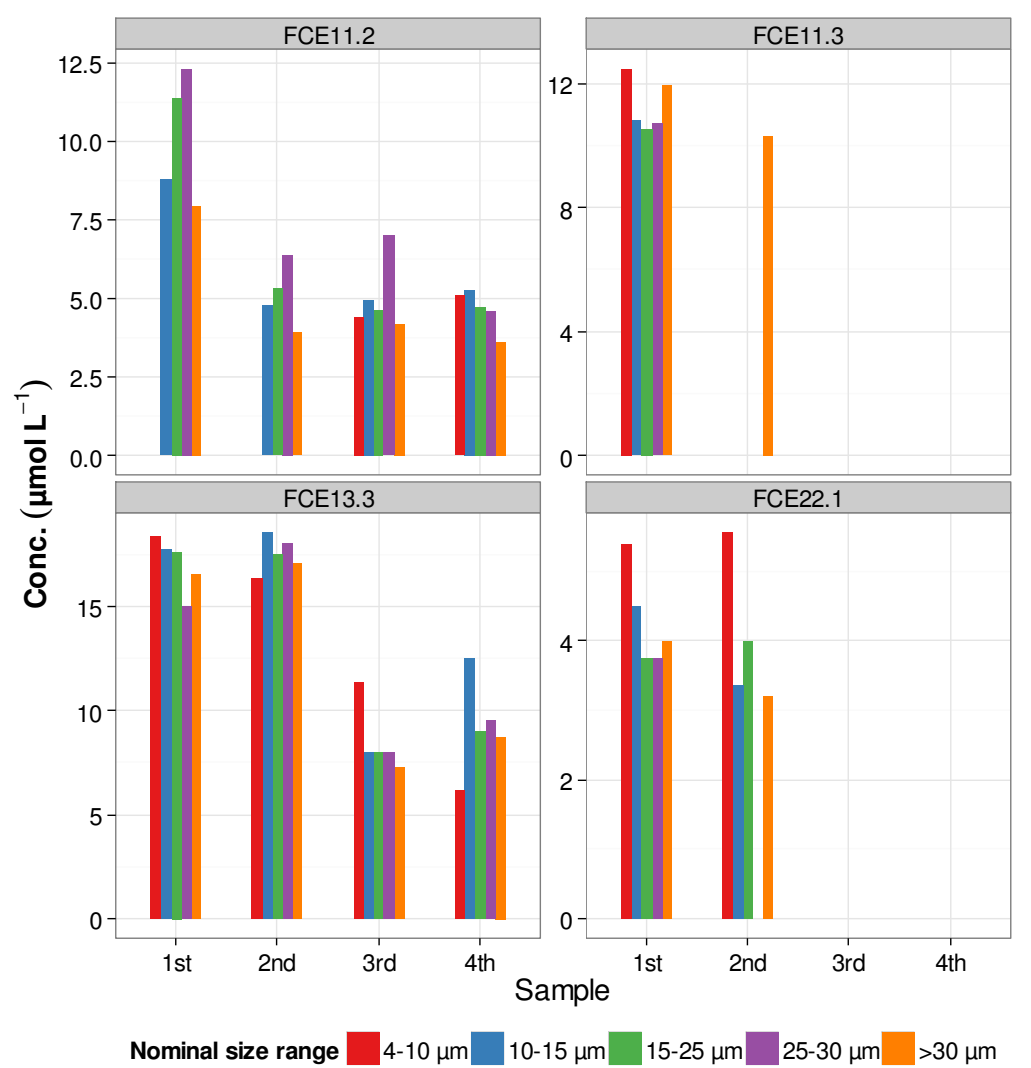

Figure S33: Size-resolved concentrations of $\mathrm{H}_{2} \mathrm{O}_{2}(\mathrm{aq})$ for individual samples from 5-stage cloud water collector.

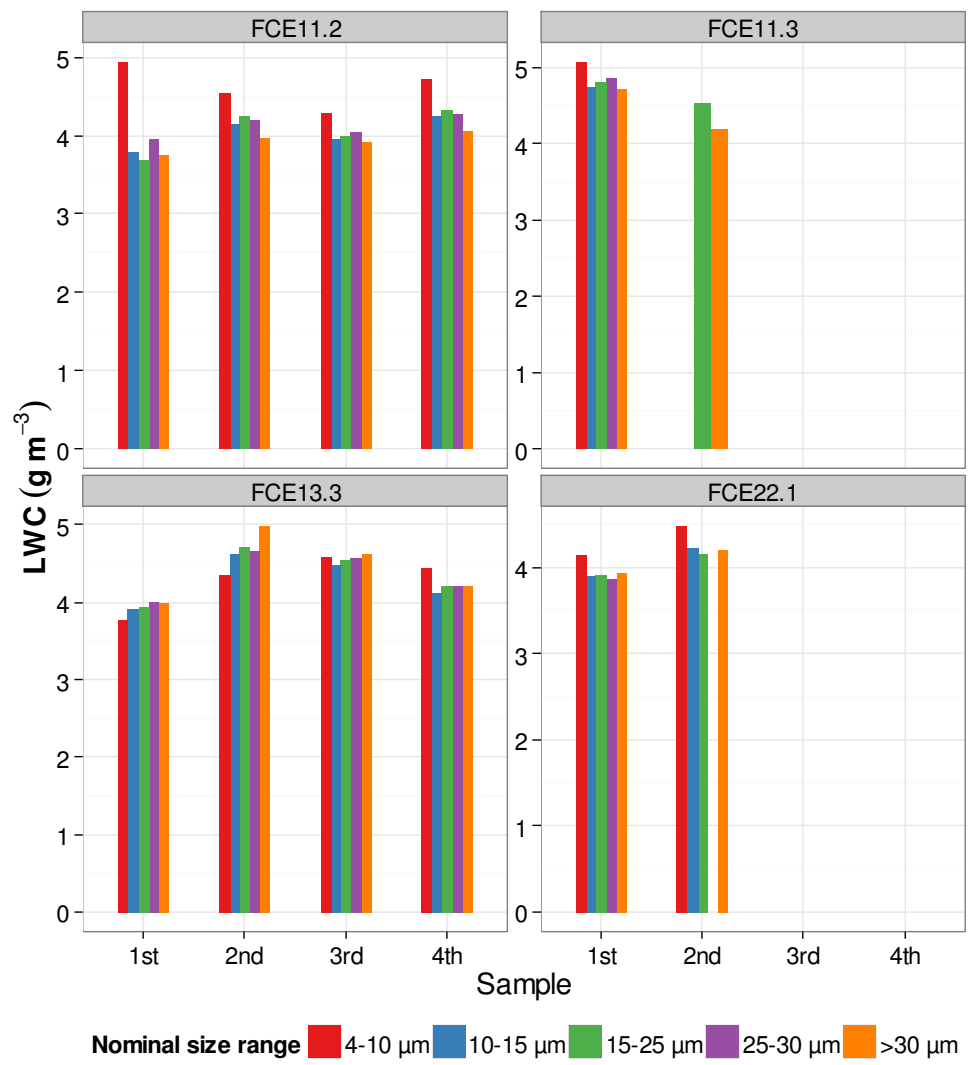

Figure S34: Size-resolved pH values for individual samples from 5-stage cloud water collector. 


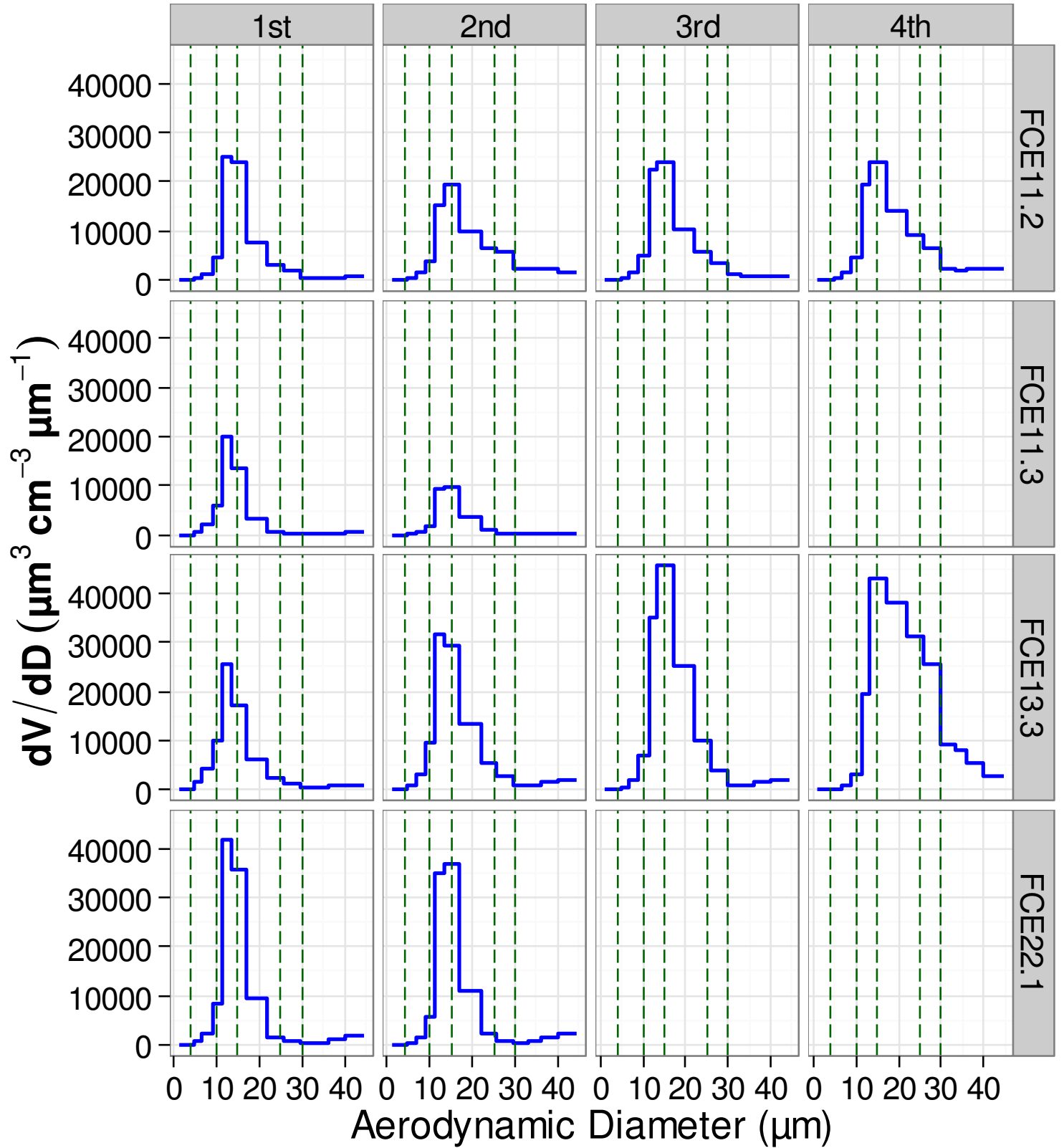

Figure S35: Mean volume size distributions of cloud droplets during individual samples of 5-stage collector. Dashed green lines indicate nominal stage cut-off diameters. 